\title{
Experimental study of flow boiling in an inclined mini-channel: effect of inclination on flow pattern transitions and pressure drops
}

\author{
Thibaut Layssac $^{1}$, Stéphane Lips ${ }^{1, *}$, and Rémi Revellin ${ }^{1}$ \\ ${ }^{1}$ Univ Lyon, CNRS, INSA-Lyon, CETHIL UMR5008, F-69621, Villeurbanne, France \\ stephane.lips@insa-lyon.fr
}

\begin{abstract}
An experimental study of R245fa two-phase flow in a $1.6 \mathrm{~mm}$ inner diameter circular channel is presented in both adiabatic and diabatic conditions. The test section is composed of a sapphire tube coated with ITO, which enables a total transparency of the evaporator. The effect of inclination on the flow patterns and the pressure drops is presented and discussed for various vapour qualities and mass velocities and a saturation temperature of $81{ }^{\circ} \mathrm{C}$, corresponding to a Bond number of 4.2. For each experimental conditions, the pressure drops are measured and the flow is visualised under eleven configurations of inclination from the vertical downward flow $\left(-90^{\circ}\right)$ to the vertical upward flow $\left(+90^{\circ}\right)$. The flow pattern transitions are compared with two flow pattern maps available in the literature. The effect of the heat flux on the flow patterns is analysed and shows the disappearance of the stratified flow for the downward flows in the case of low-inertia flows. A study of the effect of the inclination on the total and frictional pressure gradients is also led. The observations are compared with several models of the literature. These models show a good agreement to predict the pressure gradient for upward flows. Finally, the effect of the heat flux on the pressure drop variations with inclination is analysed. It shows a general increase of the pressure drops due to gravity and frictional forces with the heat flux for low vapour qualities, whatever the considered inclination. This offset decreases with the vapour quality.
\end{abstract}

Keywords: flow boiling, mini-channel, inclination angle, flow pattern, pressure drops

\begin{tabular}{|c|c|c|c|}
\hline \multicolumn{4}{|c|}{ Nomenclature } \\
\hline \multicolumn{2}{|c|}{ Roman Letters } & \multicolumn{2}{|c|}{ Dimensionless numbers } \\
\hline$d$ & diameter $(\mathrm{m})$ & $\mathrm{Bd}$ & Bond \\
\hline & mass velocity $\left(\mathrm{kg} \cdot \mathrm{m}^{-2} \cdot \mathrm{s}^{-1}\right)$ & & \\
\hline$L$ & length (m) & Subsc & ipts \\
\hline$P$ & pressure $(\mathrm{Pa})$ & & \\
\hline$s$ & symmetry (-) & botton & bottom \\
\hline$T$ & temperature $(\mathrm{K})$ & frict & frictional \\
\hline$u$ & velocity $\left(\mathrm{m} \cdot \mathrm{s}^{-1}\right)$ & grav & gravitational \\
\hline$x$ & vapour quality (-) & $h$ & homogeneous \\
\hline$z$ & abscissa (m) & in & inlet \\
\hline & & & liquid \\
\hline & Letters & lines & lines \\
\hline & & meas & measured \\
\hline$\beta$ & inclination angle (rad) & mom & momentum \\
\hline & void fraction (-) & $o$ & only \\
\hline & density $\left(\mathrm{kg} \cdot \mathrm{m}^{-3}\right)$ & out & outlet \\
\hline
\end{tabular}




\begin{tabular}{|llll|}
\hline$\sigma$ & surface tension $\left(\mathrm{N} . \mathrm{m}^{-1}\right)$ & pred & predicted \\
$\varphi$ & heat flux $\left(\mathrm{W} . \mathrm{m}^{-2}\right)$ & sat & saturation \\
$\Phi$ & two-phase flow multiplier $(-)$ & test & test \\
& top & top \\
& tot & total \\
& vap & vapour \\
& $\Delta p$ & differential pressure taps \\
& & \\
& & \\
\hline
\end{tabular}

\section{Introduction}

Flow boiling is encountered in many industrial applications, especially those which imply thermodynamic cycles or high power dissipation systems with evaporators. The efficiency of these systems depends on the geometric configuration of the evaporator. In the case of embedded applications such as heat recovery of truck exhaust gas with Organic Rankine Cycles [1], the various components have to be miniaturised and the geometry is more complicated. Consequently, the effect of the geometrical configuration, especially the confinement and the inclination angle, has to be understood to predict the global efficiency of these systems.

Many studies available in the literature deal with the effect of the experimental conditions on the pressure drops and the flow patterns for both adiabatic and diabatic two-phase flows. However, as mentioned in the review of Lips and Meyer [2], the large majority of these studies were carried out for horizontal or vertical flows.

One of the first substantial studies about the modelling of the flow pattern transitions in inclined tubes was led by Taitel and Dukler in 1976 [3]. By considering a model of smooth stratified flow in near horizontal downward flows, the authors analyse the effect of the inclination angle in terms of destabilisation of the liquid-vapour interface. Later, the mechanistic model of Barnea [4] introduces other physical mechanisms as droplets abduction to explain the observed transitions for the whole range of inclinations. Both models were developed with data obtained for adiabatic air-water flow in macrochannels (25.5 $\mathrm{mm}$ and $51 \mathrm{~mm}$ in [4]).

Weisman and Kang [5] studied experimentally the effect of the inclination on the flow pattern transitions in the case of a R113 saturated flow. The tests were carried out for upward flows in channels of $25 \mathrm{~mm}$ and $38 \mathrm{~mm}$ inner diameter and were completed by the study of Crawford et al. [6] for downward flows. These studies enabled to develop an empiric model predicting the flow patterns for the whole range of inclination.

In diabatic configuration, the studies of Bhagwat and Ghajar [7,8] and Mohseni and Akhavan-Behabadi

[9] were published more recently. Bhagwat and Ghajar [7,8] presented a study about heated air-water flow pattern transitions in a $12.7 \mathrm{~mm}$ inner diameter channel while Mohseni and Akhavan-Behabadi [9] study deals with R134a flow boiling in a $8.9 \mathrm{~mm}$ inner diameter channel. Both studies show a certain agreement with the observations which were previously done in adiabatic configuration with a 
pronounced effect of inclination on flow patterns for low-inertia flows. However, like most studies of the literature, the visualisation section of Mohseni and Akhavan-Behabadi [9] is located at the outlet of the test section. Consequently, the flow in the evaporator and the effect of heat flux cannot be directly analysed.

Several solutions were proposed in the literature to assess this problem. In the case of a rectangular channel, Ozer et al. [10] studied the evaporator temperature field with liquid crystal thermography, which enables the use of a transparent evaporator. However, only one side of the evaporator can be heated in the proposed configuration. Another solution was proposed by Narcy et al. [11] in the case of HFE7100 flow boiling in a $6 \mathrm{~mm}$ inner diameter circular channel. In this study, the evaporator is made of a sapphire tube with an ITO coating. The evaporator is then heated by Joule effect while being fully transparent. The test section also enables to measure the pressure drops in an adiabatic section located at the outlet of the evaporator.

Like the flow pattern transitions, the effect of the flow parameters on the pressure drops was largely investigated in horizontal and vertical orientations. However, the role of the gravity force orientation on the pressure drops is not well understood. Only a few studies dealing with this topic are available. The studies of Lips and Meyer [12] and Adelaja et al. [13] on flow condensing of R134a can be mentioned. Bhagwat and Ghajar [7,8] studied the effect of inclination on the pressure drops in heated air-water flows. All these studies show a significant effect of the inclination on the pressure drops for low-inertia two-phase flows. However, there is a lack of diversity in the literature configurations, especially in terms of confinement, and no general conclusion can be drawn.

The present article is based on two test campaigns led on the effect of the inclination on flow boiling of R245fa in a transparent evaporator. The experimental setup and the experimental database are presented in the first section. The effects of the inclination on the flow patterns and the pressure drops are presented respectively in the second and third sections in both adiabatic and diabatic conditions. In these two parts, comparisons are made with models available in the literature.

\section{Presentation of the experimental setup and database}

\subsection{Description of the test section}

The experimental setup used in the current study is adapted from the test bench of Charnay et al. [14]. This test bench enables the study of flow boiling of R245fa by controlling the saturation pressure with the two-phase tank and the mass velocity with a gear pump and a micro-valve (Figure 1). The study of the flow patterns and the pressure drops is led by the mean of a test section presented in Figure 2. The test section is composed of an inclinable aluminium frame which supports the loop, composed of a preheater and an evaporator. A LED and a high-speed camera are used to study the flow patterns directly in the evaporator. The $2000 \mathrm{~mm}$ stainless steel preheater is heated by Joule effect, which enables the control of the vapour quality at the inlet of the evaporator. Due to the low mass velocities and the low 
heat rates $(<15 \mathrm{~W}$ ) which were considered in the present study, the calculation of the inlet vapour quality required to take into consideration the preheater heat losses. The final error on the energy balance was less than $10 \%$. Layssac [15] provides more details about the methodology to calculate the heat losses.

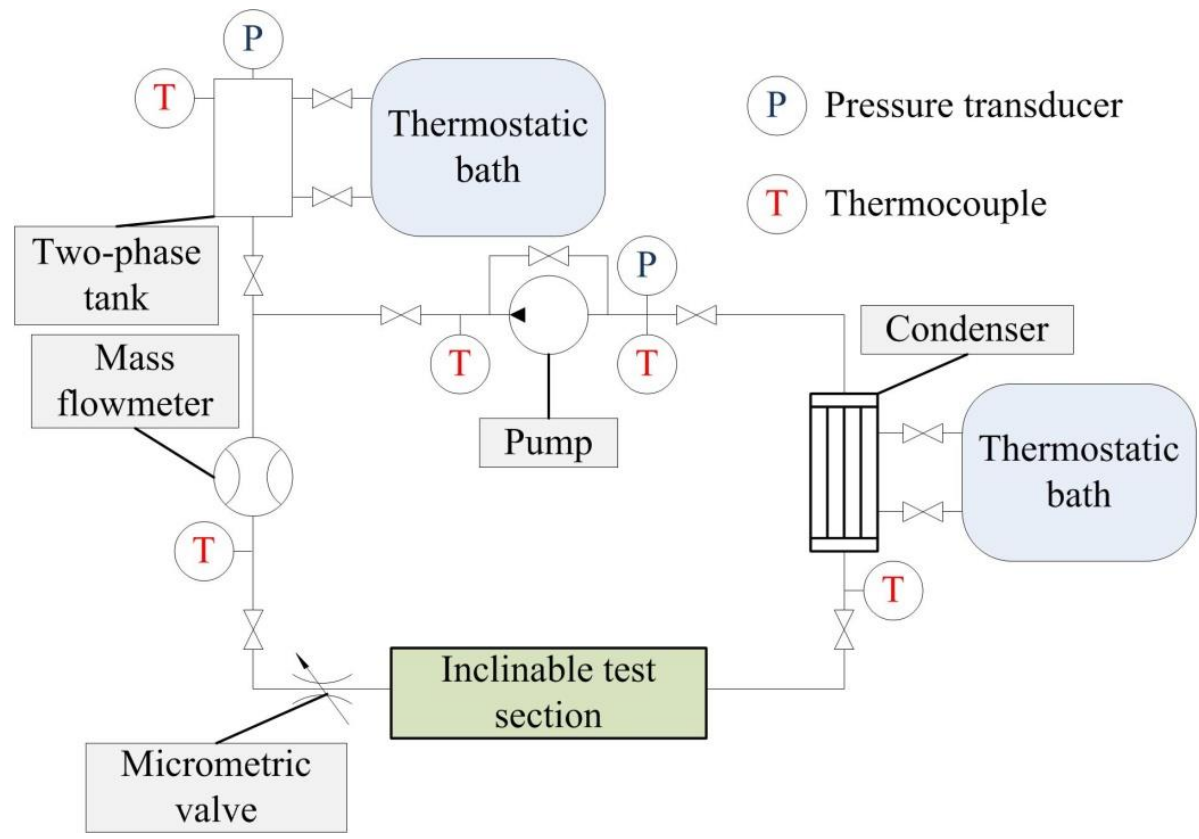

Figure 1: Schematic of the test bench

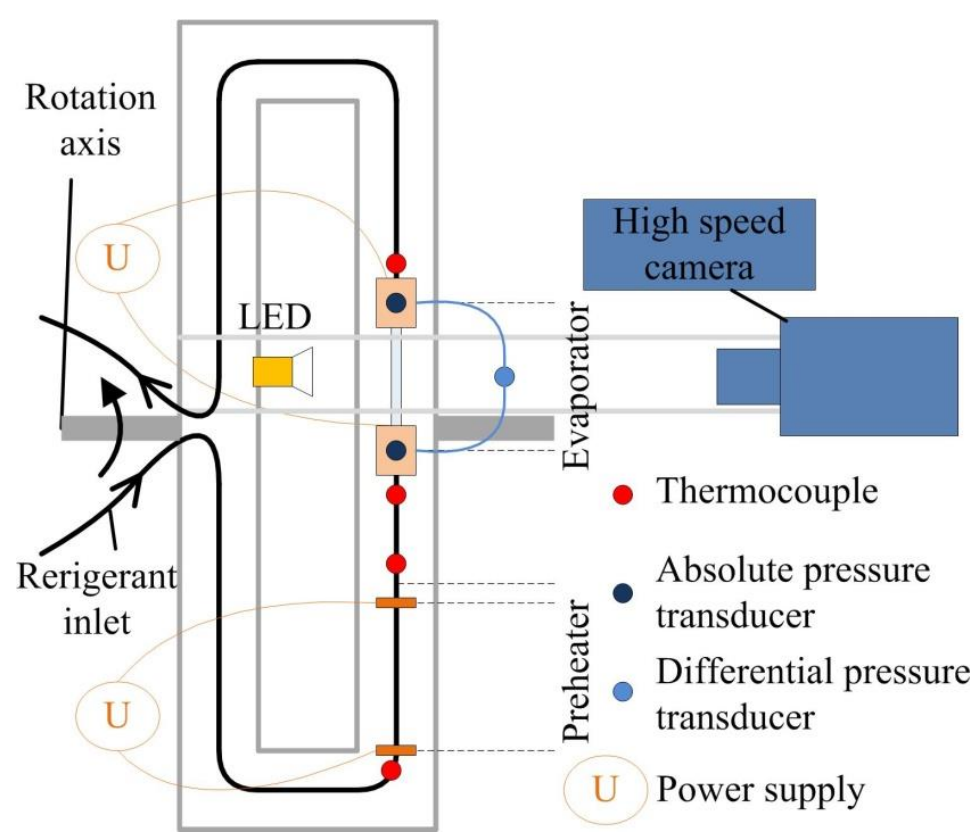

Figure 2: Schematic of the inclinable test section (top view)

The transparent evaporator, presented in Figure 3, enables the study of R245fa saturated two-phase flow in adiabatic and diabatic conditions. It is composed of a sapphire tube whose length is $200 \mathrm{~mm} \pm 1.0$ $\mathrm{mm}$ and inner diameter is $1.6 \mathrm{~mm} \pm 0.15 \mathrm{~mm}$. The sapphire tube is recovered with a $1 \mu \mathrm{m}$ thickness 
transparent conductive ITO coating. In the present study, its resistivity is equal to $450 \pm 10 \Omega$. Due to the variability of the ITO resistivity with the temperature and aging, both supply tension and intensity had to be passively controlled during the test campaign. This experimental process enables the study of the effect of the heat flux on flow patterns and pressure drops.

The pressure drop between the inlet and the outlet of the evaporator is measured with a Keller KE23D differential pressure transducer ranging $0-200$ mbar. The distance between the two pressure taps is 270 $\mathrm{mm}$. The pressure drop measurement uncertainty is $\pm 0.40 \mathrm{mbar}$. Since the sapphire tube is not thermally insulated, a thermal model is used to take into account the heat losses and to be able to calculate the vapour quality. As for the preheater, the error on the energy balance in the evaporator is less than $10 \%$. The two energy balances result in a mean vapour quality uncertainty of \pm 0.05 . The control of the saturation conditions is ensured at the inlet of the evaporator with a $\mathrm{K}$ type thermocouple whose uncertainty is $\pm 0.25 \mathrm{~K}$ and an absolute pressure transducer whose uncertainty is 0.07 bar.

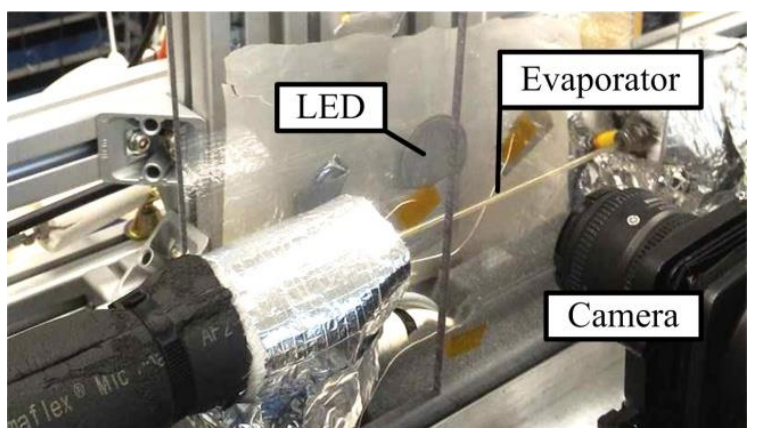

a) Photo

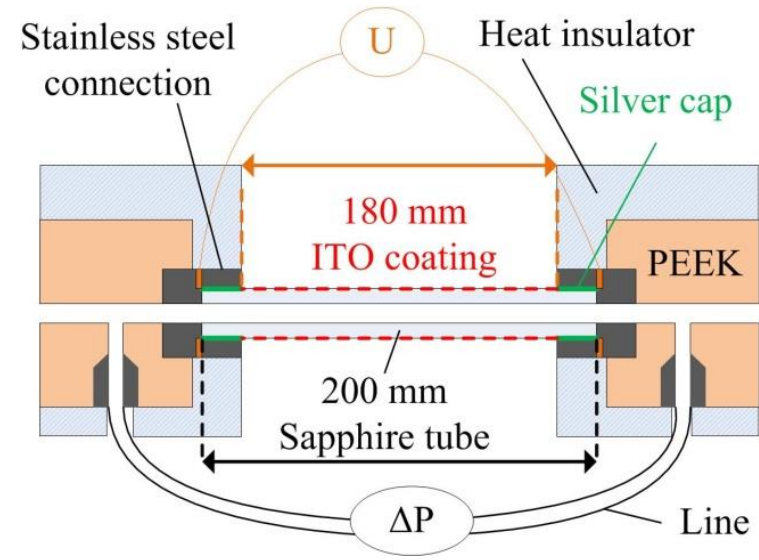

b) Schematic

Figure 3: Photo (a) and schematic (b) of the evaporator

\subsection{Experimental conditions}

Two test campaigns were led with a mean saturation temperature of $81^{\circ} \mathrm{C}$ in adiabatic conditions and with a heat flux of $13.5 \mathrm{~kW} \cdot \mathrm{m}^{-2}$. The choice of these parameters was motivated by considerations about the heat transfer coefficient uncertainty and the heterogeneity of the ITO coating. For each set of mass velocity and vapour quality, the pressure drop was measured and the two-phase flow was visualised for 
inclination angles of $-90^{\circ}, 60^{\circ},-45^{\circ},-30^{\circ},-15^{\circ}, 0^{\circ}, 15^{\circ}, 30^{\circ}, 45^{\circ}, 60^{\circ}$ and $90^{\circ}$. The ranges and the fluctuations of the experimental parameters for each angle of inclination are summarised in Table 1 . The fluctuations are calculated as the mean standard deviation of each series of experiment made with a given mass velocity and vapour quality.

Table 1: Ranges of experimental parameters

\begin{tabular}{lccc} 
Heat flux density & $\varphi=0 \mathrm{~kW} \cdot \mathrm{m}^{-2}$ & $\varphi=13.5 \mathrm{~kW} \cdot \mathrm{m}^{-2}$ & Fluctuations \\
\hline Number of data points & 176 & 198 & - \\
Hydraulic diameter $d$ & $1.6 \mathrm{~mm}$ & $1.6 \mathrm{~mm}$ & - \\
Saturation temperature $T_{\text {sat }}$ & $80.9^{\circ} \mathrm{C}$ & $80.9^{\circ} \mathrm{C}$ & $0.2^{\circ} \mathrm{C}$ \\
Mass velocity $G$ & $100 \rightarrow 300 \mathrm{~kg} \cdot \mathrm{m}^{-2} \cdot \mathrm{s}^{-1}$ & $150-300 \mathrm{~kg} \cdot \mathrm{m}^{-2} \cdot \mathrm{s}^{-1}$ & $3 \mathrm{~kg} \cdot \mathrm{m}^{-2} \cdot \mathrm{s}^{-1}$ \\
Vapour quality $x$ & $0.06 \rightarrow 0.67$ & $0.03 \rightarrow 0.85$ & 0.01 \\
Inclination angle $\beta$ & $-90 \rightarrow 90^{\circ}$ & $-90^{\circ} \rightarrow 90^{\circ}$ & $<0.5^{\circ}$ \\
\hline
\end{tabular}

In the case of an imposed heat flux, it is noticeable that the flux is sufficiently low to avoid a too large variation of vapour quality in the test section. With a mass velocity of $150 \mathrm{~kg} \cdot \mathrm{m}^{-2} \cdot \mathrm{s}^{-1}$, a heat flux density of $13.5 \mathrm{~kW} \cdot \mathrm{m}^{-2}$ results in a difference of vapour quality lower than 0.15 between the inlet and the outlet of the evaporator. The vapour quality is then calculated at the middle of the evaporator where the flow is visualised, which enables an easy comparison of the adiabatic and diabatic results.

The current ranges of experimental parameters focus on the low inertia driven two-phase flow. This is motivated by the fact that the inclination affects the two-phase flow when the gravity forces are strong compared to the inertia forces, which corresponds to a low vapour Froude number. Additionally, the configuration of the study is also characterized by a low diameter compared with the previous studies dealing with the effect of inclination on two-phase flows. In the present study, the Bond number is equal to 4.2, which corresponds to the case of a mini-channel. According to the literature review of Karayiannis et Mahmoud [16], the present tube diameter indeed typically corresponds to the transition between micro and macro channel, even if no general consensus can be found on the accurate value of this transition. The Bond number is calculated as follows:

$\mathrm{Bd}=\frac{g\left(\rho_{l i q}-\rho_{v a p}\right) d^{2}}{\sigma}$

It enables the study of the effect of gravity forces for a relatively high confinement.

\subsection{Flow pattern characterization}

An optical measurement technique was previously developed by Donniacuo et al. [17] to measure the two-phase flow liquid film thickness in a $2.95 \mathrm{~mm}$ diameter glass tube. This method was adapted to the present configuration. For each experimental condition, a set of 1363 frames is recorded with an acquisition frequency of 2000 frames. $\mathrm{s}^{-1}$, a mean resolution of 200 pixels. $\mathrm{mm}^{-1}$ and a greyscale pixel 
depth of 256. It typically corresponds to a recording type of about $0.7 \mathrm{~s}$, which is sufficient to describe the flow as no fluctuation having a higher time period was observed.

This technique is completed with a post-processing using Matlab, which enables to obtain the symmetry and the proportion of the liquid plugs of the flow.

The Matlab program used for the estimation of the two-phase flow symmetry is described in Layssac et al. [18]. A symmetry parameter $s$ is introduced to represent the symmetry level of the two-phase flow, defined as follows:

$s=1-\frac{t_{\text {bottom }}-t_{\text {top }}}{d}$

where $t_{\text {bottom }}$ and $t_{\text {top }}$ are respectively the bottom and top liquid film thicknesses.

It is equal to 1 when the two-phase flow is symmetric. The limit case of $s=0$ corresponds to an almost fully liquid flow with very small bubbles vanishing at the top inner wall.

The proportion of plugs is then calculated for each frame sequence, which corresponds to the percentage of frames where a liquid plug is present. This parameter is calculated by considering the fact that when a plug is observed, the frame is brighter and the mean value of the frame pixels is consequently higher. Once the symmetry parameter and the proportion of plugs are obtained, three flow patterns are defined and characterized: intermittent, stratified and annular flows. The two quantitative criteria defined to discriminate the flow patterns are presented in Table 2.

Time evolution frames with detected profiles of vapour-liquid interfaces are also presented in Table 2. The time evolution frame is obtained by extracting the profile at the middle abscissa for each frame of the acquisition sequence. All the profiles are disposed side by side. An image of the time evolution of the flow is then readable by considering the evolution of this image with its abscissa. This method enables to have a global view of the evolution of the flow during the recording time. Videos of intermittent, stratified, and annular flows are provided in Electronic Annex 1. These videos present the flow with a scrolling frequency of 25 frames. $\mathrm{s}^{-1}$, which corresponds to a slowing factor of 80 .

Table 2: Quantitative criteria for flow pattern characterization

\begin{tabular}{|c|c|c|c|c|}
\hline Flow pattern & Representative frame & Time evolution frame & Symmetry $s$ & Plug percentage \\
\hline Intermittent & & & - & $>1 \%$ \\
\hline Stratified & 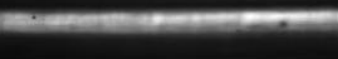 & & $<0.95$ & $<1 \%$ \\
\hline Annular & & 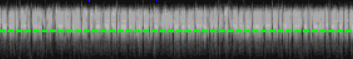 & $>0.95$ & $<1 \%$ \\
\hline
\end{tabular}




\subsection{Mean pressure gradient calculation}

The mean pressure gradient inside the evaporator is deduced from the measurement of the Keller KE23D differential pressure transducer. The calculation of the evaporator pressure drops $\left(\Delta P_{\text {test }}\right)$ requires taking into consideration the hydrostatic pressure drops inside the pressure lines $\left(\Delta P_{\text {lines }}\right)$ (Figure 3 ) connecting the taps to the transducer as follows:

$\Delta P_{\text {test }}=\Delta P_{\text {meas }}+\Delta P_{\text {lines }}$

Since R245fa is liquid in the pressure lines, the pressure drop in the lines is calculated as:

$\Delta P_{\text {lines }}=\rho_{\text {liq }} g L_{\Delta p} \sin \beta$

where $L_{\Delta p}$ is the distance between the two pressure taps.

Consequently, the mean total pressure gradient in the evaporator is obtained with the following equation:

$\frac{\overline{d P_{t o t}}}{d z}=\frac{\Delta P_{\text {meas }}}{\Delta z}+\rho_{\text {liq }} g \sin \beta$

To be able to compare the experimental results to models available in the literature, the pressure gradient due to the frictional forces only is also calculated. The total pressure drop is generally considered to be composed of three terms, which come from the gravity forces $\left(\Delta P_{\text {grav }}\right)$, the frictional forces $\left(\Delta P_{\text {frict }}\right)$, and a momentum term $\left(\Delta P_{\text {mom }}\right)$ :

$\Delta P_{\text {tot }}=\Delta P_{\text {frict }}+\Delta P_{\text {grav }}+\Delta P_{\text {mom }}$

The momentum term $\Delta P_{m o m}$ is estimated as:

$\Delta P_{\text {mom }}=G^{2}\left[\left(\frac{(1-x)^{2}}{\rho_{\text {liq }}(1-\varepsilon)}+\frac{x^{2}}{\rho_{\text {vap }} \varepsilon}\right)_{o u t}-\left(\frac{(1-x)^{2}}{\rho_{\text {liq }}(1-\varepsilon)}+\frac{x^{2}}{\rho_{\text {vap }} \varepsilon}\right)_{\text {in }}\right]$

The pressure drop due to the gravity forces is calculated with the following equation:

$\Delta P_{\text {grav }}=\left[\varepsilon \rho_{\text {vap }}+(1-\varepsilon) \rho_{\text {liq }}\right] g L_{\Delta p} \sin \beta$

Consequently, the calculation of the two previous terms requires the knowledge of the mean, inlet and outlet void fractions inside the evaporator. Since the confinement is particularly pronounced in the present study, it has been chosen to avoid any void fraction direct measurements. The void fraction is thus calculated with the model of Bhagwat and Ghajar [19] which is the only model taking into consideration the effect of the inclination on the void fraction for the whole range of inclination. This choice is discussed in more details in section 4.1.

In the case of a diabatic flow, the acceleration term is then calculated and is equal to $-0.1 \mathrm{kPa}^{-1}$ with a mass velocity of $150 \mathrm{~kg} \cdot \mathrm{m}^{-2} \cdot \mathrm{s}^{-1}$ and $-0.3 \mathrm{kPa} \cdot \mathrm{m}^{-1}$ with a mass velocity of $300 \mathrm{~kg} \cdot \mathrm{m}^{-2} \cdot \mathrm{s}^{-1}$. Due to the range of total pressure gradient of the present study, this term is systematically neglected for the calculation of the pressure gradient due to frictional forces.

The pressure gradient due to frictional forces is then calculated as follows: 
$\frac{\overline{d P_{\text {fruct }}}}{d z}=\frac{\Delta P_{\text {meas }}}{L_{\Delta p}}+\varepsilon\left(\rho_{\text {liq }}-\rho_{\text {vap }}\right) g \sin \beta$

Unlike the total pressure gradient, the uncertainty for the estimation of the pressure gradient due to the frictional forces mainly comes from the void fraction estimation of the model of Bhagwat and Ghajar [19], The void fraction uncertainty from this model is $30 \%$ for void fractions lower than $0.5,20 \%$ for void fraction between 0.5 and 0.75 and $7.5 \%$ for void fraction higher than 0.75 . In the present study, the main uncertainty of the pressure gradient due to the frictional forces is around $0.7 \mathrm{kPa} \cdot \mathrm{m}^{-1}$ while it is around $0.4 \mathrm{kPa} \cdot \mathrm{m}^{-1}$ for the total pressure gradient.

\section{Effect of inclination on flow patterns}

\subsection{Adiabatic flow pattern transitions}

The three flow patterns observed during the adiabatic flow test campaign were intermittent, stratified and annular. Negative angles correspond to the cases of downward flows while positive angles correspond to upward flows. The intermittent flow pattern is characterised by the alternation of liquid plugs and vapour slugs and mostly appear for low vapour qualities $(<0.2)$ in the case of vertical downward flow $\left(\beta=-90^{\circ}\right)$ and upward flows $\left(\beta \geq 0^{\circ}\right)$. The stratified flow pattern is characterised by the presence of a vapour core at the upper part of the flow, slightly eccentric in the present case, and mostly appears for low vapour qualities $(x<0.2)$, low mass velocity $\left(G=150 \mathrm{~kg} \cdot \mathrm{m}^{-2} \cdot \mathrm{s}^{-1}\right)$ and downward or horizontal flows $\left(-60^{\circ} \leq \beta \leq 0^{\circ}\right)$. The annular flow pattern, characterised by a centred vapour core flow surrounded by a liquid film, is mainly observed when the vapour quality is higher than 0.2 . Matrixes of time evolution frames are presented in Electronic Annex 2 for mass velocities of 100, 150 and $300 \mathrm{~kg} \cdot \mathrm{m}^{-}$ ${ }^{2} \cdot \mathrm{s}^{-1}$.

The variations of the flow patterns with the inclination angle and the vapour quality for mass velocities of 100,150 and $300 \mathrm{~kg} \cdot \mathrm{m}^{-2} \cdot \mathrm{s}^{-1}$ is summarized in Figure 4 . In the case of a mass velocity of $100 \mathrm{~kg} \cdot \mathrm{m}^{-2} \cdot \mathrm{s}^{-}$ ${ }^{1}$, the data points are obtained only for vapour qualities lower than 0.3 due to problems of dynamic stabilization of the flow with the present test bench. As previously observed by Lips and Meyer [20] in the case of R134a condensation, it is observed that inclination affects the flow patterns only for low vapour qualities $(x<0.3)$ and low mass velocities $\left(G=100\right.$ and $\left.150 \mathrm{~kg} \cdot \mathrm{m}^{-2} \cdot \mathrm{s}^{-1}\right)$. It may be explained by the fact that the two-phase flow orientation has an effect on flow patterns only when the gravity forces are not negligible compared to the inertia, shear and capillary forces. When the vapour quality and the mass velocity increase, the vapour inertia increases and the flow becomes annular, being insensitive to orientation. 


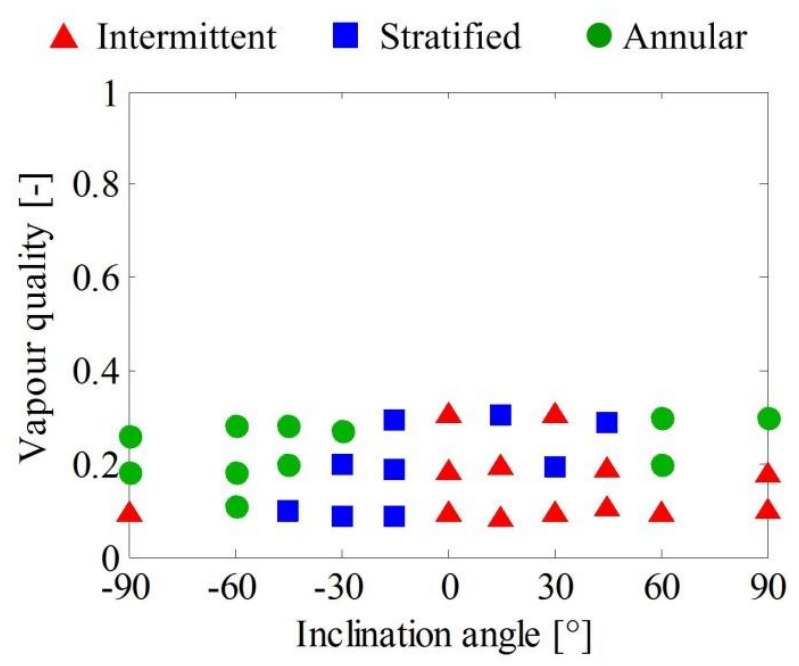

a) $G=100 \mathrm{~kg} \cdot \mathrm{m}^{-2} \cdot \mathrm{s}^{-1}$

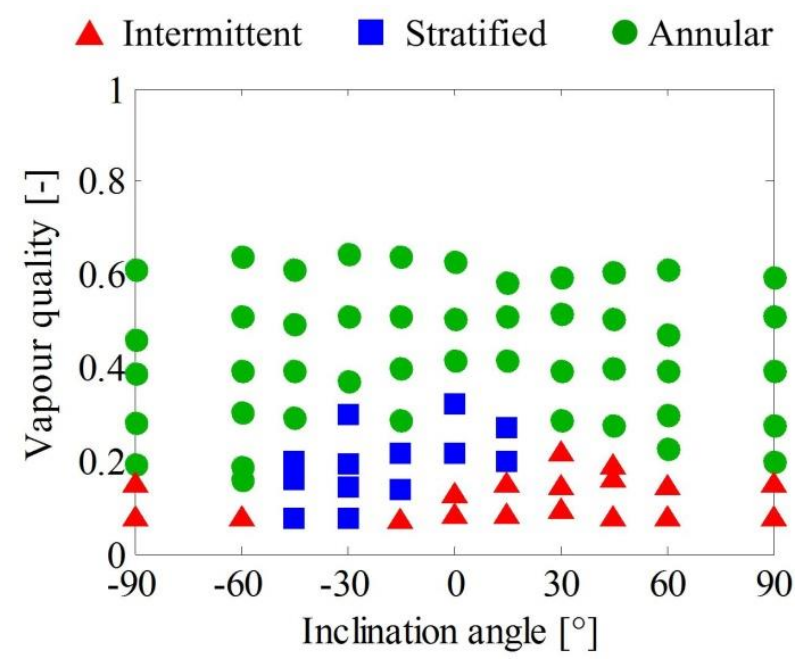

b) $G=150 \mathrm{~kg} \cdot \mathrm{m}^{-2} \cdot \mathrm{s}^{-1}$

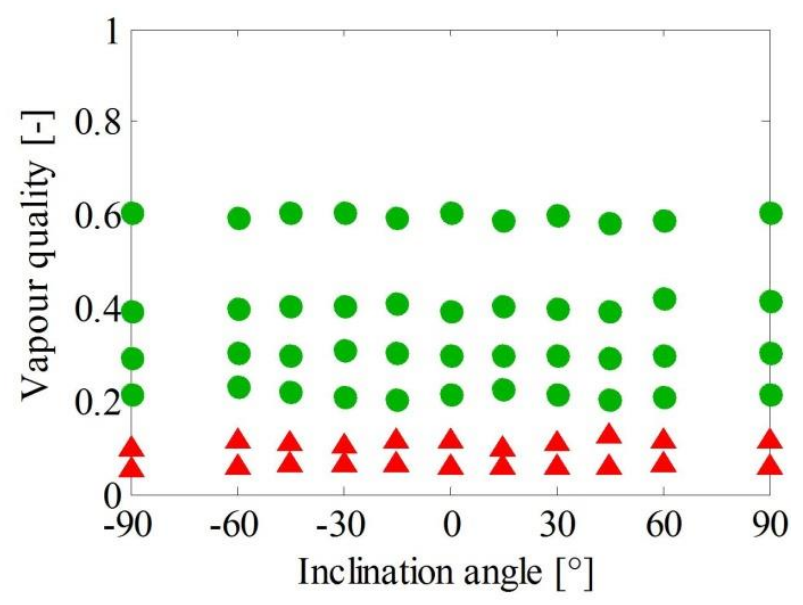

c) $G=300 \mathrm{~kg} \cdot \mathrm{m}^{-2} \cdot \mathrm{s}^{-1}$

Figure 4: Variations of the flow patterns with the vapour quality and the inclination angle with $G=$ $100 \mathrm{~kg} \cdot \mathrm{m}^{-2} \cdot \mathrm{s}^{-1}$ (a), $G=150 \mathrm{~kg} \cdot \mathrm{m}^{-2} \cdot \mathrm{s}^{-1}$ and $G=300 \mathrm{~kg} \cdot \mathrm{m}^{-2} \cdot \mathrm{s}^{-1}(\mathrm{c})\left(\varphi=0 \mathrm{~kW} \cdot \mathrm{m}^{-2}\right)$ 


\subsection{Comparison with models available in the literature}

A few flow pattern maps were proposed in the literature to predict the evolution of the two-phase flow patterns with the inclination angle. In the present study, it is proposed to compare the experimental results with the predictions of Barnea [4] and Crawford et al. [5,6] models.

Barnea [4] flow pattern maps are based on a mechanistic model which was developed with air-water flow experiments for channels of 25.5 and $51 \mathrm{~mm}$ of inner diameter. It enables to take into account the transitions between smooth stratified, wavy stratified, annular, churn, slug-plug, dispersed bubbly and elongated bubble flows. To simplify the presentation of the results and to match with the present criteria, these flow patterns are gathered into three categories, namely:

- Stratified flows (S), gathering smooth and wavy stratified flows

- Annular flows (A), regrouping smooth and wavy annular flows

- Intermittent flows (I), gathering slug-plug and elongated bubble flows

It is noticeable that in the present study, dispersed bubbly and churn flows were not observed, which can be explained by the low diameter of the evaporator.

Figure 5 presents the comparison between the observed flow patterns and the predictions of Barnea [4] flow pattern transition model. Although this model was obtained under conditions which are far from the present one (macro-channel, air-water flow), it predicts well the flow pattern transitions, especially the intermittent-annular one. The majority of the stratified flows are well predicted except for those which were observed for upward flows $\left(\beta=0^{\circ}\right.$ and $\left.30^{\circ}\right)$. However, it is remarkable that these flows were already observed in the literature [21,22] and actually correspond to a limit case of a slug-plug flow where the bottom liquid does not manage to reach the top of the flow. These flows were named protoslug by Nicholson et al. [21].

The good agreement between the model of Barnea [4] and the experiments, despite the fact that this model was develop for other configuration, tends to show that the mechanisms considered in the model were well identified. According to Barnea [4], the transition between stratified and non-stratified regimes is mainly due to the Kelvyn-Helmholtz instabilities which are strongly affected by the liquid film thickness, and thus the tube inclination, through the liquid hold-up. According to the same author, the transition between annular and intermittent regimes is mostly due to the blockage of the gas core and to the circumferential instabilities of the annular liquid film flowing downward near the wall. This one is actually only affected by the inclination angle for low mass fluxes as for high mass fluxes, the shear stresses dominates the gravitational forces. This effect seems to be well predicted by the model of Barnea [4]. 
Flow orientation
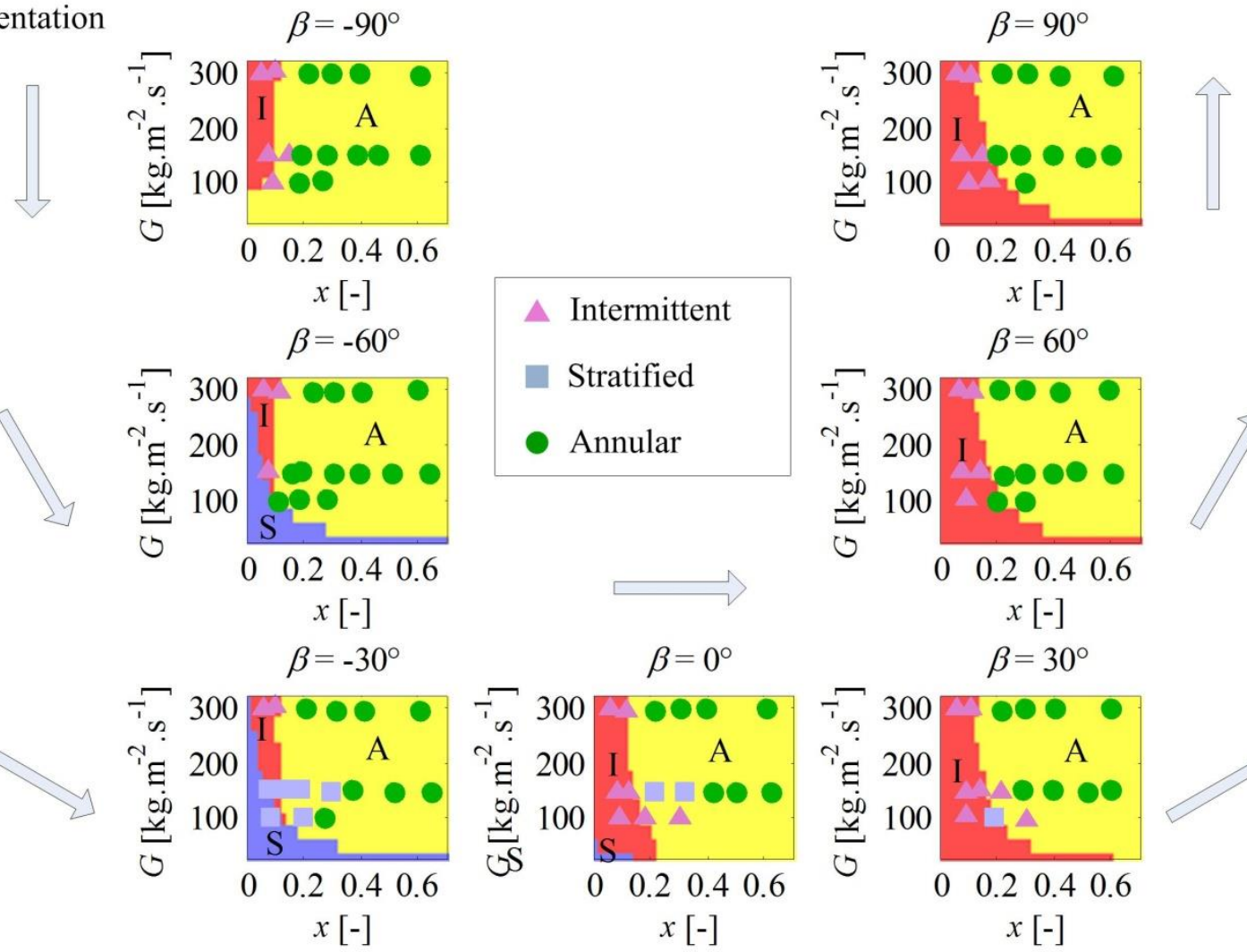

Figure 5: Comparison of experimental flow patterns with Barnea [4] flow pattern maps

Figure 6 shows the comparison between the observed flow patterns and the predictions of Crawford et al. [5,6] flow pattern transition model. This empirical model was developed from the visualisation of R113 saturated two-phase flows in two different macro-channels of $25 \mathrm{~mm}$ and $38 \mathrm{~mm}$. A worse agreement is observed between the predictions of Crawford et al. [5,6] model and the experimental database. Especially, this model does not consider the effect of the inclination on the intermittent to annular flow transition while it was observed during the test campaign. It may be explained by the fact that contrary to the model of Barnea [4], more empirical dimensionless correlations were used to develop this model and its predictions cannot be extrapolated for configurations for which it was not developed. 
Flow

orientation

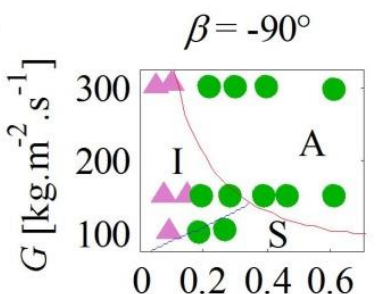

$\begin{array}{lllll}0 & 0.2 & 0.4 & 0.6\end{array}$

$x[-]$

$$
\beta=-60^{\circ}
$$$$
\text { T }
$$

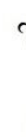

$\Delta$ Intermittent

Stratified

- Annular

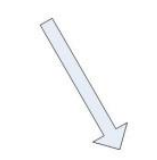

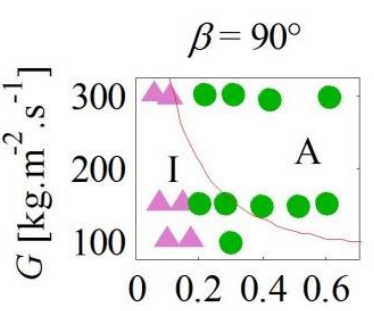

$x[-]$

$\beta=60^{\circ}$

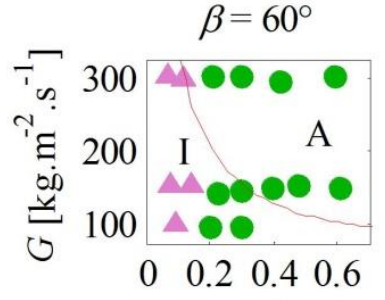

$x[-]$

$\beta=30^{\circ}$
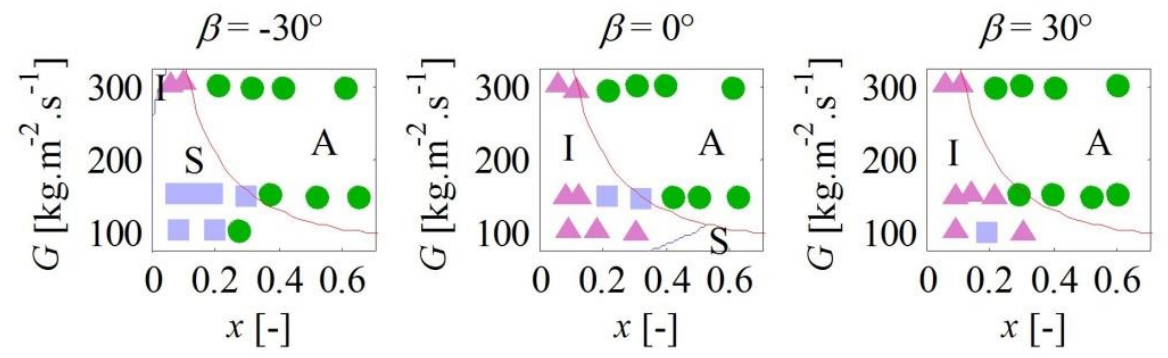

Figure 6: Comparison of experimental flow patterns with Crawford et al. [5,6] flow pattern maps

As a conclusion, the mechanistic flow pattern transition model of Barnea [4] predicts well the flow patterns in the present configuration while the empirical model of Crawford et al. [5,6] is less accurate, especially for near vertical orientations. It seems that the physical equilibria taken into consideration in the model of Barnea [4] describe well the actual phenomenology. Consequently, the pronounced confinement in the present configuration slightly affect the transitions compared with the reference macro-channel case of Barnea [4], which is consistent with the intermediate Bond number equal to 4.2. Further studies about the effect of inclination with lower diameters are required to understand the coupling between the gravity forces orientation and the confinement on the liquid-vapour interface equilibrium.

\subsection{Effect of heat flux on flow pattern transitions}

Owing to the transparency of the evaporator, the flow can be directly visualised while the evaporator is heated by Joule effect. It enables the observation of the effect of heat flux on the two-phase flow patterns. Figure 7 shows representative frames of intermittent flows $\left(G=150 \mathrm{~kg} \cdot \mathrm{m}^{-2} \cdot \mathrm{s}^{-1}, x=0.06, \beta=45^{\circ}\right)$ and annular flows $\left(G=150 \mathrm{~kg} \cdot \mathrm{m}^{-2} \cdot \mathrm{s}^{-1}, x=0.5, \beta=45^{\circ}\right)$ in the case of an adiabatic flow (a) and with an imposed heat flux of $13.5 \mathrm{~kW} . \mathrm{m}^{-2}$ (b). Corresponding videos are provided in Electronic Annex 1. 
The comparison of the frames in the case of an intermittent flow shows that the heat flux clearly affects the flow, which is due to the nucleation phenomenon. Small bubbles are created by nucleation, which leads to a larger diversity of bubble sizes compared to the adiabatic case where bubbles are able to coalesce into a long slug.

In the case of an annular flow, the flow is slightly affected by the heat flux. Nucleation appears to affect the flow by the creation of small bubbles. However, the intensity of the phenomenon is clearly lower compared to the intermittent case. It can be explained by the fact that nucleation intensity decreases when the film thickness decreases, leading to a lower local overheat.

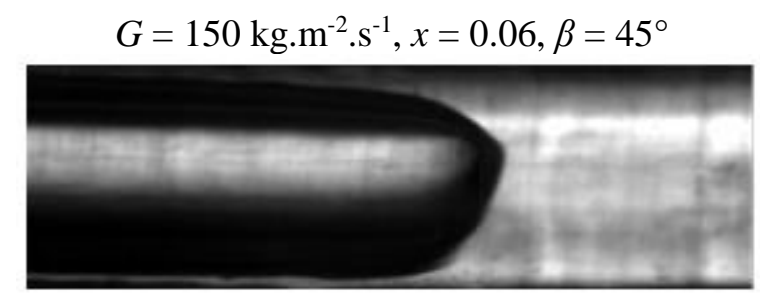

a) $\varphi=0 \mathrm{~kW} \cdot \mathrm{m}^{-2}$

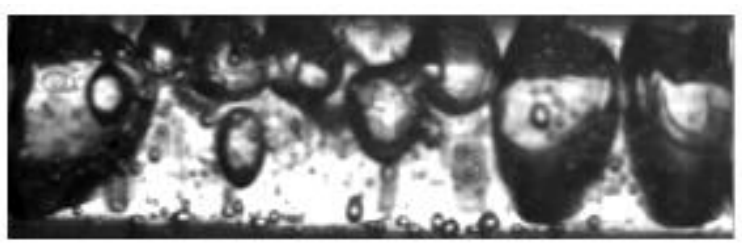

b) $\varphi=13.5 \mathrm{~kW} \cdot \mathrm{m}^{-2}$

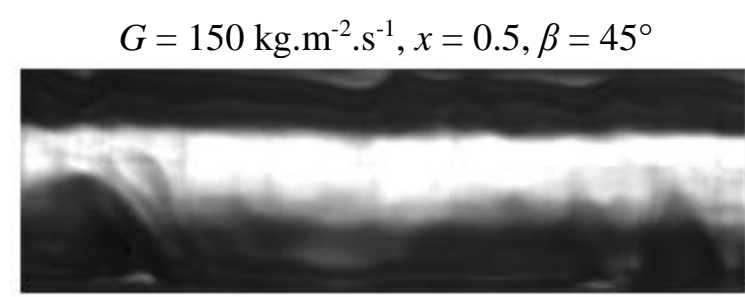

a) $\varphi=0 \mathrm{~kW} \cdot \mathrm{m}^{-2}$

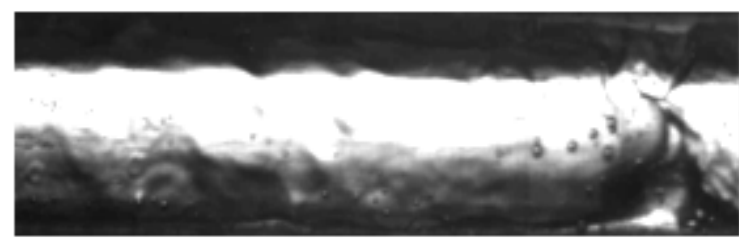

b) $\varphi=13.5 \mathrm{~kW} \cdot \mathrm{m}^{-2}$

Figure 7: Example of the heat flux effect on the flow pattern; representative frames of the flow without heat flux (a) and with a heat flux of $13,5 \mathrm{~kW} \cdot \mathrm{m}^{-2}(\mathrm{~b})$

The effect of heat flux on the flow pattern maps is summarized on Figure 8 for mass velocities of $150 \mathrm{~kg} \cdot \mathrm{m}^{-2} \cdot \mathrm{s}^{-1}$ (a) and $300 \mathrm{~kg} \cdot \mathrm{m}^{-2} \cdot \mathrm{s}^{-1}$ (b). Graphs of Figure 8 show the occurrence of flow patterns in the case of adiabatic flow (filled regions A, S I) compared with the case of an imposed heat flux of $13,5 \mathrm{~kW} \cdot \mathrm{m}^{-2}$ (markers). The heat flux clearly affects the flow pattern transitions in the case of a mass velocity of $150 \mathrm{~kg} \cdot \mathrm{m}^{-2} \cdot \mathrm{s}^{-1}$. In the conditions of the present experiments, the stratified flow pattern, observed in adiabatic conditions is no longer observed when a heat flux is imposed. The nucleation seems to perturb the flow, which prevents the formation of this flow pattern. However, this observation cannot be generalized to bigger tube as for macro channel, stratified flow regime can be observed even when boiling occurs. There must be a threshold value of tube diameter (or Bond number) that leads to the behaviour observed in the present study. To quantify this phenomenon, it should be interesting to study the effect of nucleate boiling on the flow stability and to include this mechanism in the flow pattern map of Barnea [4]. According to the mechanisms already considered by the latter, the nucleate boiling can either affect the Kelvyn-Helmholtz instabilities, or generate another type of instability.

Although the heat flux clearly affects the flow pattern transitions for the low vapour inertia cases, the intermittent to annular transition does not seem particularly impacted by the nucleation in the present 
study. It could be explained by the fact that nucleate boiling does not affect the radial instabilities of the annular liquid film, which is the main mechanism considered by Barnea [4] for this transition.

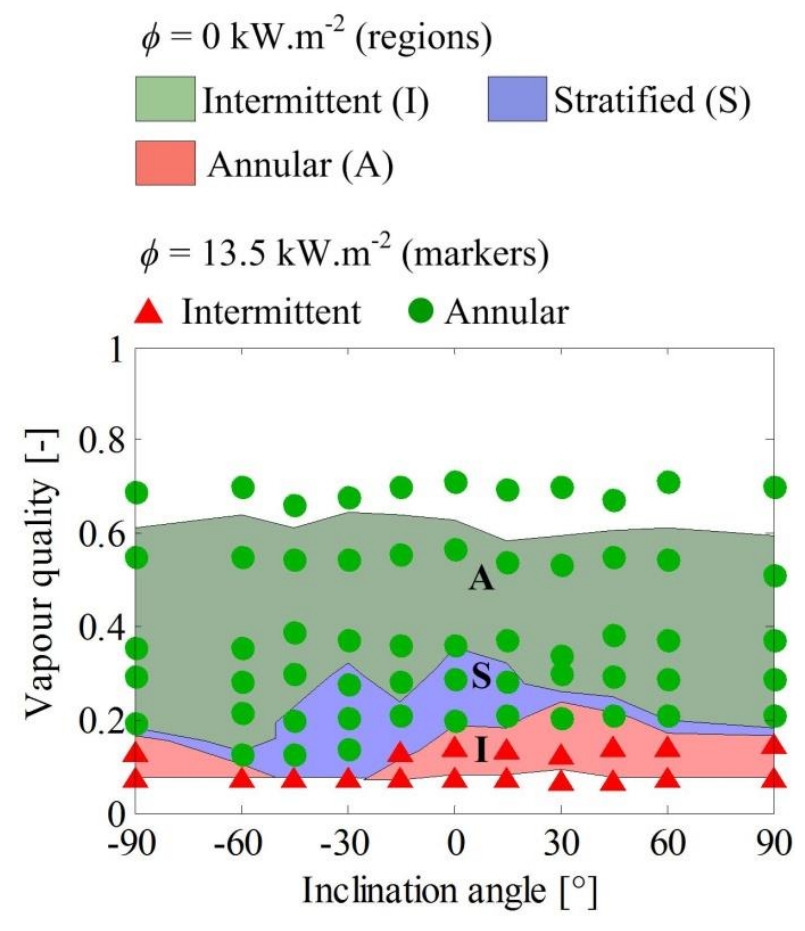

a) $G=150 \mathrm{~kg} \cdot \mathrm{m}^{-2} \cdot \mathrm{s}^{-1}$

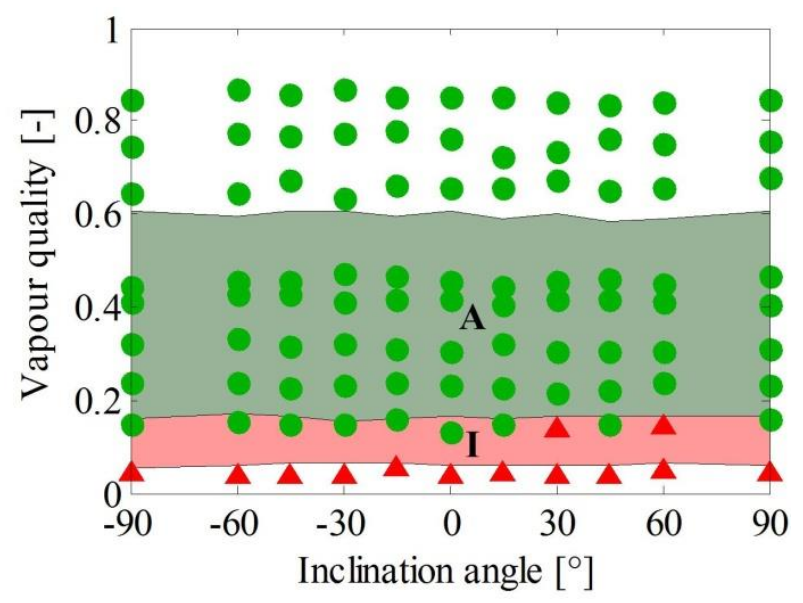

b) $G=300 \mathrm{~kg} \cdot \mathrm{m}^{-2} \cdot \mathrm{s}^{-1}$

Figure 8: Variations of the flow patterns with $\varphi=13,5 \mathrm{~kW} \cdot \mathrm{m}^{-2}$ compared to the adiabatic conditions

As a conclusion, the study of the effect of the heat flux on the flow pattern transitions in the case of a confined inclined flow shows clear differences between adiabatic and diabatic cases. As a consequence, considering an adiabatic flow pattern model to estimate the heat transfer coefficient does not seem much appropriate. More data points, obtained in various experimental conditions, are required to understand the interaction between nucleation and two-phase flow, especially concerning the effect of the heat flux intensity and the tube diameter. It highlights the importance of using transparent evaporator in order to enable a good description of the flow configuration. 


\section{Effect of inclination and heat flux on the pressure drops}

\subsection{Void fraction prediction in inclined flow}

According to equations (6), (7) and (8), the calculation of the momentum, gravitational and frictional pressure drops requires the knowledge of the void fraction. Among the several kinds of models of the literature used for the prediction of the void fraction, the drift flux models of Rouhani and Axelsson [23], for vertical flows, and Steiner [24], for horizontal flows are largely employed. Due to the recent development of inclined experimental setups, the model of Bhagwat and Ghajar [19] is the only model to predict void fraction for the entire range of inclination.

The experimental determination of the void fraction is very difficult but an estimation can be calculated by means of an image processing in the case of intermittent or annular flow. In the present section, the small tube diameter does not enable an accurate determination of the liquid film thickness for annular flow and it is thus proposed to compare the accuracy of the models of the literature $[19,23,24]$ with void fraction calculations made with the intermittent flow data only.

In the case of a plug/slug flow pattern, the void fraction can be calculated from the slug velocity as follows:

$\varepsilon=\frac{x G}{\rho_{\text {vap }} u_{\text {slug }}}$

where $u_{\text {slug }}$ is the velocity of the slug.

The slug velocity is obtained from a frame post-processing with Matlab. The apparition of the plugs is detected with the same considerations as previously presented. When a plug/slug interface is detected, the velocity of the slug, considered equal to the interface velocity, is calculated by cross correlating the frames and then calculating their delay. The variations of the calculated void fraction with the inclination angle is compared with the evolution predicted by the models of Bhagwat and Ghajar [19], Rouhani and Axelsson [23], Steiner [24] and the homogeneous flow model in the Figure 9 in the case of a flow whose mass velocity is $150 \mathrm{~kg} \cdot \mathrm{m}^{-2} \cdot \mathrm{s}^{-1}$ and vapour quality is 0.08 . 


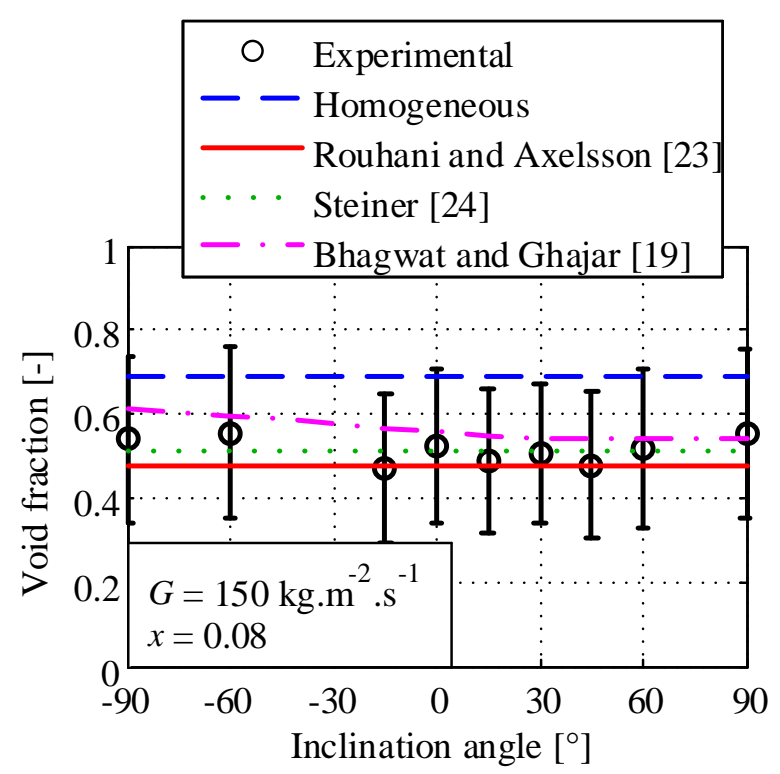

Figure 9: Variations of the void fraction with the inclination angle for a mass velocity of $150 \mathrm{~kg} \cdot \mathrm{m}^{-2} \cdot \mathrm{s}^{-1}$ and a vapour quality of 0.08 ; comparison of the experimental results with three predictive models

The void fraction measurements are subject to important uncertainties, which are mainly due to the relative uncertainties on the vapour quality and on the tube diameter. Despite these high uncertainties, Figure 9 shows a weak evolution of the void fraction with inclination, which is well predicted by Bhagwat and Ghajar [19] model. The three drift flux flow models are in good agreement with the calculations contrary to the homogeneous flow model. This observation can be enlightened by the fact that slip ratios were observed to be higher than 1.4 for all the experimental data, which is inconsistent with the main hypothesis of the homogeneous flow model. The models accuracy is analyzed by representing the evolution of their predictions as a function of experimental void fraction in Figure 10 and by considering their Mean Absolute Percentage Error (MAPE) for the present dataset. MAPE is defined as follows:

$M A P E=\frac{1}{N} \sum\left|\frac{\varepsilon_{\text {pred }}-\varepsilon_{\text {meas }}}{\varepsilon_{\text {meas }}}\right|$

where $N$ is the sample size. 


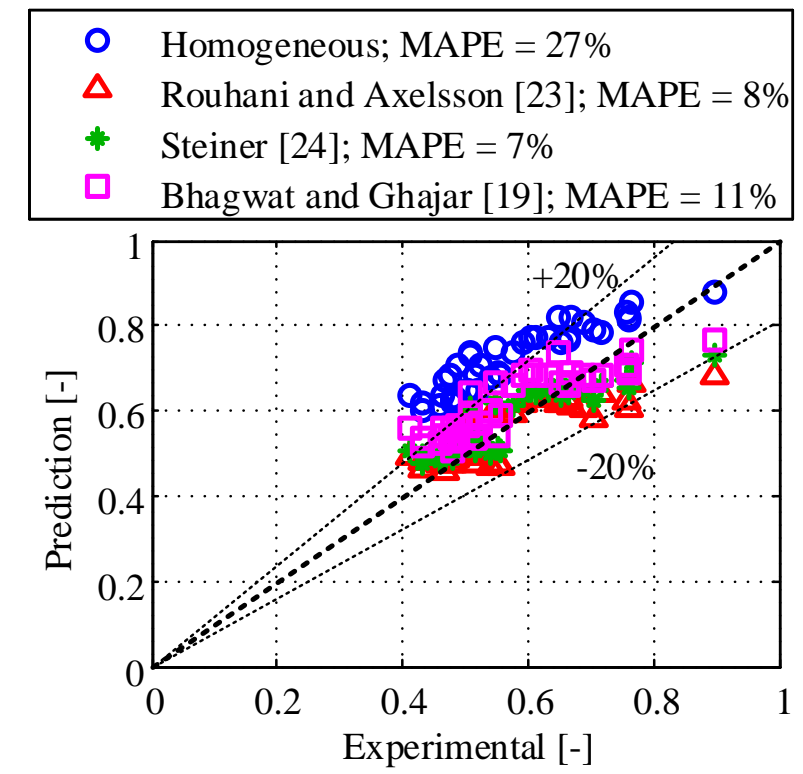

Figure 10: Statistical analysis of the void fraction models

The chart of Figure 10 shows the three drift flux models sensibly have the same accuracy to predict the void fraction. Consequently, in the present work, the model of Bhagwat and Ghajar [19] is chosen to calculate the gravity and momentum terms of pressure drop, this model being the only one taking into consideration the effect of inclination.

\subsection{Experimental study of adiabatic flows}

The total and frictional pressure drops inside the evaporator are affected by experimental conditions, especially its orientation in the case of an adiabatic flow. Figure 11 presents the evolution of the total and frictional pressure gradients (respectively (a) and (b)) as a function of the sinus of the inclination angle for various vapour qualities and a mass velocity of $150 \mathrm{~kg} \cdot \mathrm{m}^{-2} \cdot \mathrm{s}^{-1}$.

As previously observed for flow patterns, Figure 11 (a) shows the pressure drop is particularly affected by orientation for low-inertia flows corresponding to a vapour quality lower than 0.3. A transition appears for an angle of $-15^{\circ}$ : the total pressure drop remains almost constant for lower angles while it clearly increases for higher angles. This behaviour was previously observed by Spedding et al. [25] in the case of an adiabatic air-water flow and by Lips and Meyer [20] in the case of R134a condensation in macro-channels. It is linked to the observed transition between stratified and intermittent flows. Concerning the frictional pressure gradient presented in Figure 11 (b), a transition is also observed between downward flows and upward flows. For low-inertia flows, the frictional pressure gradient decreases for downward flows $\left(\beta<0^{\circ}\right)$ and its variations are less pronounced for upward flows $\left(\beta>0^{\circ}\right)$. For vapour qualities higher than 0.3 (Figure 11), the vapour inertia forces are stronger, the two-phase flow is annular and both total and frictional pressure drops depend only slightly on the inclination.

The observations for both frictional and total pressure gradient made with low vapour qualities in the case of a mass velocity of $100 \mathrm{~kg} \cdot \mathrm{m}^{-2} \cdot \mathrm{s}^{-1}$ (Figure 12) are consistent with those made with a mass velocity of $150 \mathrm{~kg} \cdot \mathrm{m}^{-2} \cdot \mathrm{s}^{-1}$. Moreover, it is noticeable that in the case of a flow with a mass velocity of $100 \mathrm{~kg} \cdot \mathrm{m}^{-}$ 
${ }^{2} . \mathrm{s}^{-1}$ and a vapour quality of 0.09 , the calculated frictional pressure gradient is negative for inclination angles of $60^{\circ}$ and $90^{\circ}$. This is apparently due to the calculation of this term which depends on the void fraction. The uncertainties on the estimation of the void fraction for low vapour qualities may affect the calculation of the frictional pressure drop and then results in a negative value.

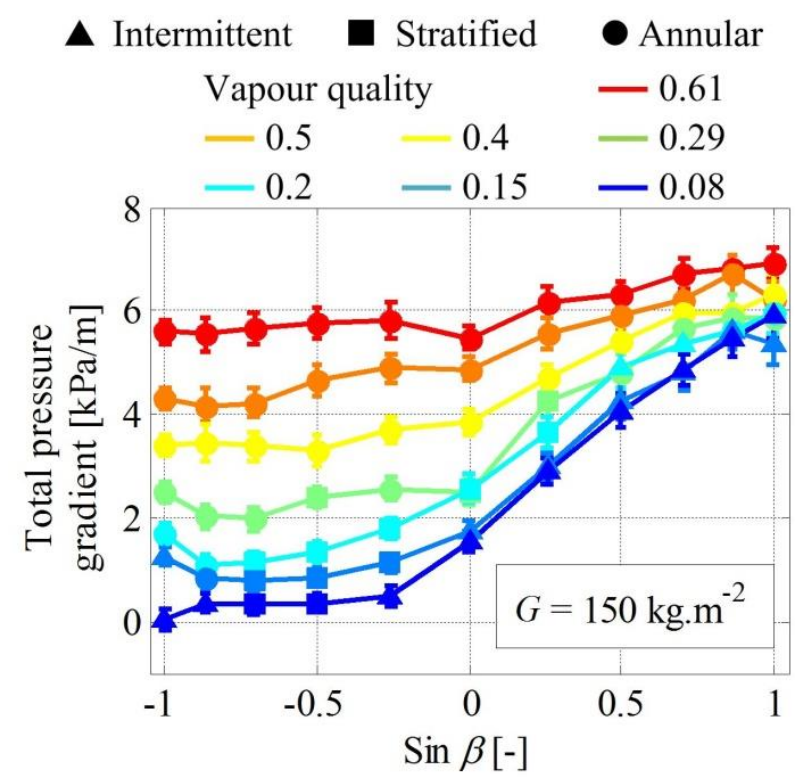

a) Total pressure gradient

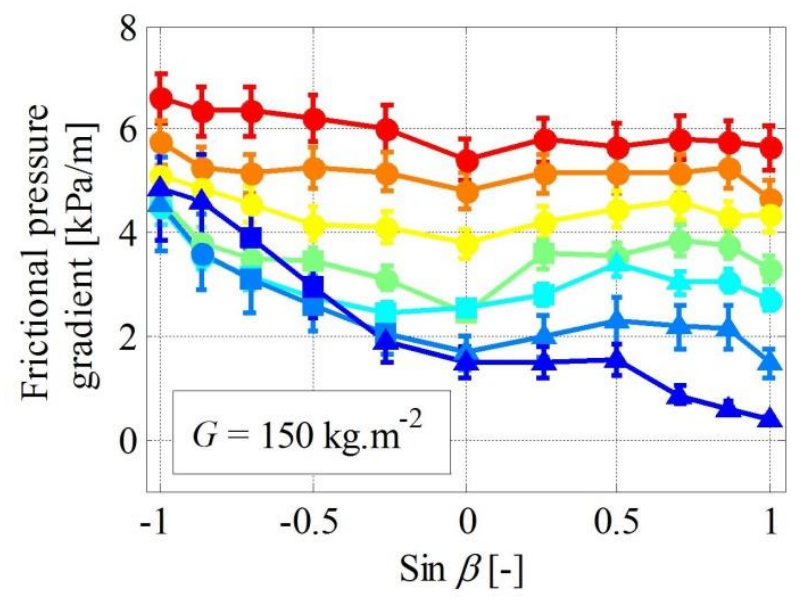

b) Frictional pressure gradient

Figure 11: Variations of the total pressure gradient (a) and the frictional pressure gradient (b) as a function of the inclination angle for a mass velocity of $150 \mathrm{~kg} \cdot \mathrm{m}^{-2} \cdot \mathrm{s}^{-1}$ 
$\boldsymbol{\Delta}$ Intermittent $\boldsymbol{\square}$ Stratified $\bullet$ Annular

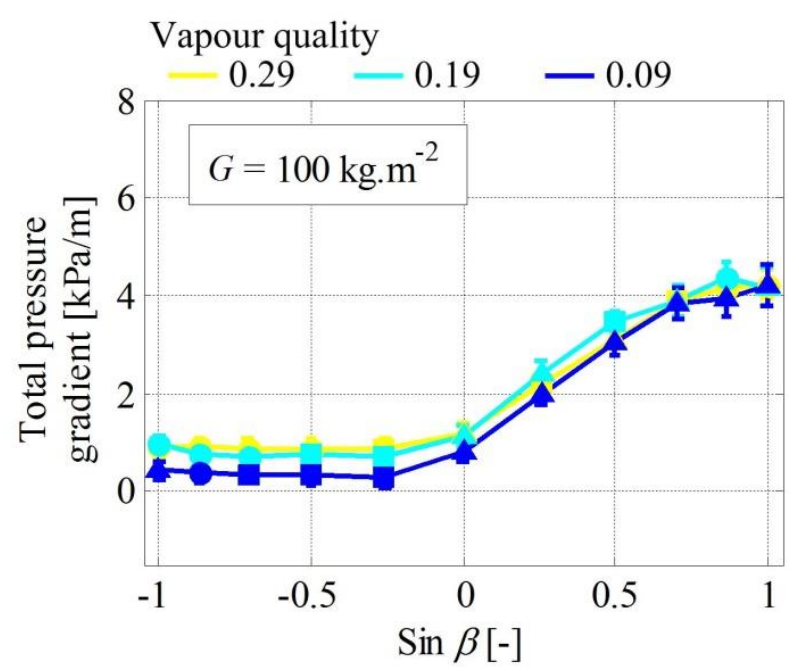

a) Total pressure gradient

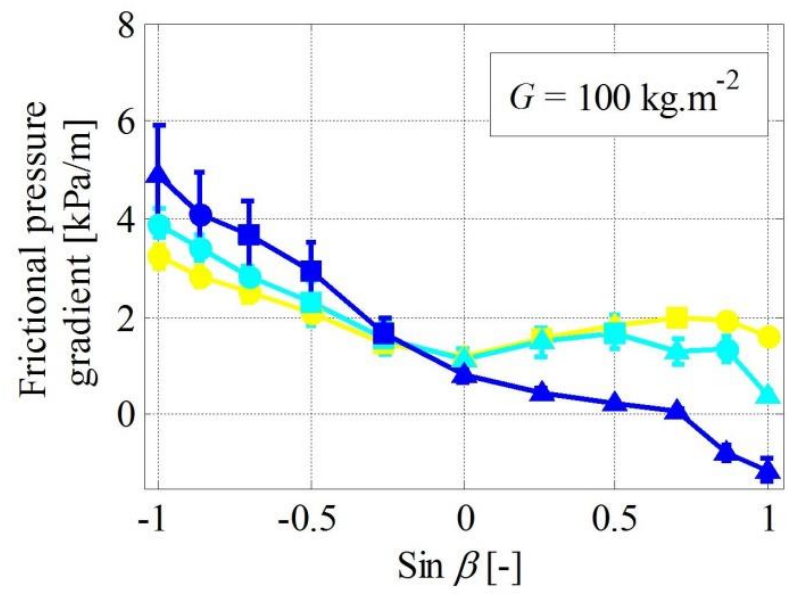

b) Frictional pressure gradient

Figure 12: Variations of the total pressure gradient (a) and the frictional pressure gradient (b) as a function of the inclination angle for a mass velocity of $100 \mathrm{~kg} \cdot \mathrm{m}^{-2} \cdot \mathrm{s}^{-1}$

Figure 13 shows the variations of the total (a) and the frictional (b) pressure gradients with inclination for various vapour qualities and a mass velocity of $300 \mathrm{~kg} \cdot \mathrm{m}^{-2} \cdot \mathrm{s}^{-1}$. Due to higher vapour inertia, a lower effect of inclination on pressure drops is observed. 


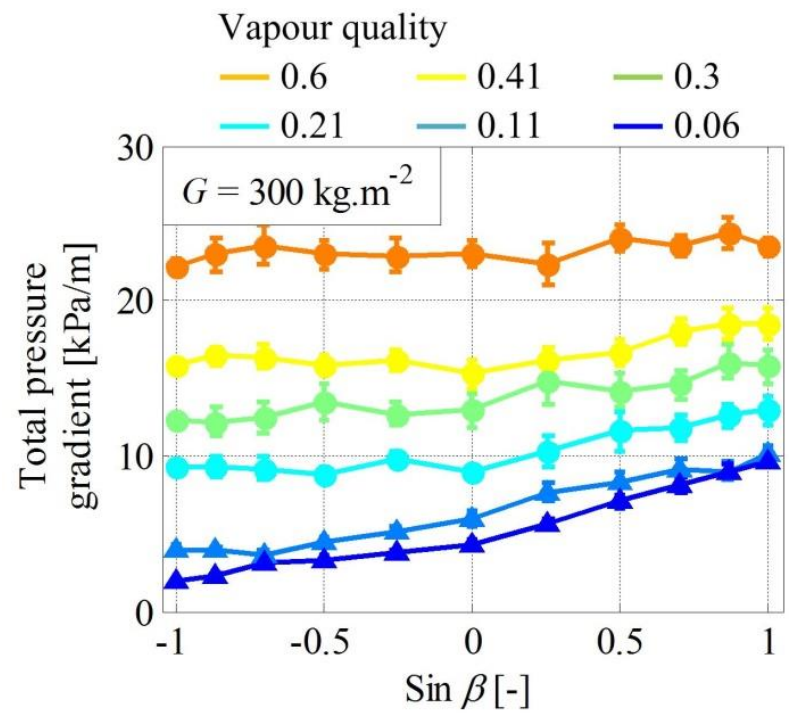

c) Total pressure gradient

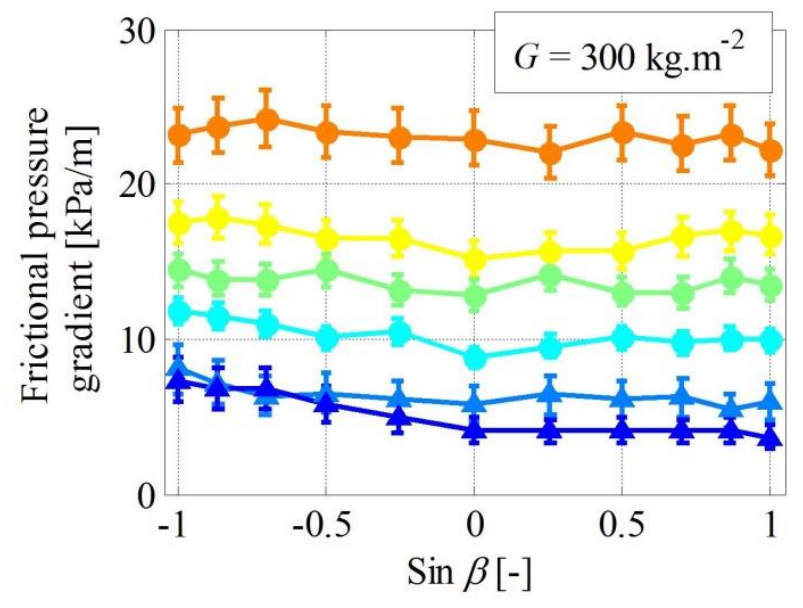

d) Frictional pressure gradient

Figure 13: Variations of the total pressure gradient (a) and the frictional pressure gradient (b) as a function of the inclination angle for a mass velocity of $300 \mathrm{~kg} \cdot \mathrm{m}^{-2} \cdot \mathrm{s}^{-1}$

To conclude, the pronounced variations of the pressure drops with inclination for the low-inertia flows show the importance of the gravity forces on the pressure drops in the present case. Although the confinement is more pronounced than in the literature, the pressure drops are influenced by the gravity field orientation in the present study, showing macro-channel behaviour. However, more experiments are required to define accurately the transitions between the various behaviours available in the literature.

\subsection{Comparison with pressure drop models}

The present total pressure drop dataset is compared with various models of the literature. Three kinds of models are considered: homogeneous flow models, separated flow models and the empirical model of Beggs and Brill [26]. For each model, the accuracy is analyzed in terms of Mean Absolute Error (MAE), Mean Error (ME), Percentage of Experimental Data Captured within $\pm 50 \%$ (PEDC50), 
Percentage of upward flow $\left(\beta \geq 0^{\circ}\right)$ Data Captured within $\pm 50 \%$ with (PEDC50+), and Percentage of downward flow $\left(\beta<0^{\circ}\right)$ Data Captured within $\pm 50 \%$ (PEDC50-). The MAE and ME are calculated as follows:

$M A E=\frac{1}{N} \sum\left|\Delta P_{\text {pred }}-\Delta P_{\text {meas }}\right|$

$M E=\frac{1}{N} \sum\left(\Delta P_{\text {pred }}-\Delta P_{\text {meas }}\right)$

The choice of absolute statistical indicators as MAE and ME is motivated by the fact that the experimental total pressure drop can be negative because of the gravitational pressure drop, which forbids to use MAPE, defined as:

$M A P E=\frac{1}{N} \sum\left|\frac{\Delta P_{\text {pred }}-\Delta P_{\text {meas }}}{\Delta P_{\text {meas }}}\right|$

However, the accuracy of the models can still be compared by this mean. Percentage of Experimental Data Captured is used to keep information about the accuracy of the correlations in terms of relative indicator.

The predictions of ten homogeneous flow models, twelve separated flow models and the model of Beggs and Brill [26] were tested. The results in terms of statistical indicators are presented in Table 3.

Table 3: Total pressure drop $\left(\Delta P_{t o t}\right)$ prediction accuracy of ten homogeneous flow models $\left(\varepsilon=\varepsilon_{h}\right)$ and twelve separated flow models $\left(\varepsilon=\varepsilon_{\text {Bhagwat }}\right)$

MAE [Pa] ME [Pa $\quad$ PEDC50 [\%] PEDC50+ [\%] PEDC50- [\%]

Homogeneous flow

\begin{tabular}{lccccc}
\hline McAdams et al. [27] & 759 & -759 & 81 & 97 & 63 \\
Cicchiti et al. [28] & 623 & -622 & 75 & 95 & 54 \\
Dukler et al. [29] & 785 & -785 & 80 & 98 & 58 \\
Beattie and Whalley [30] & 716 & -716 & 73 & 88 & 56 \\
Lin et al. [31] & 837 & -837 & 71 & 92 & 47 \\
Fourar et Bories [32] & 709 & -709 & 79 & 92 & 64 \\
Davidson et al. [33] & 7845 & 7805 & 14 & 19 & 8 \\
Garcia et al. [34] & 806 & -806 & 78 & 97 & 55 \\
Awad and Muzychka 1 [35] & 626 & -626 & 74 & 93 & 53 \\
Awad and Muzychka 2 [35] & 794 & -794 & 78 & 98 & 55 \\
\hline
\end{tabular}

Separated flow

\begin{tabular}{lccccc}
\hline Lockhart and Martinelli [36] & 408 & 148 & 72 & 85 & 56 \\
Friedel [37] & 532 & -498 & 85 & 98 & 69 \\
Müller-Steinhagen and Heck [38] & 655 & -644 & 78 & 100 & 54
\end{tabular}




\begin{tabular}{lccccc} 
Mishima et al. [39] & 1419 & -1413 & 15 & 27 & 0 \\
Tran et al. [40] & 604 & 470 & 69 & 83 & 53 \\
Chen et al. [41] & 1298 & -1292 & 18 & 34 & 0 \\
Yu et al. [42] & 1552 & -1547 & 10 & 19 & 0 \\
Hwang and Kim [43] & 1230 & -1224 & 20 & 37 & 0 \\
Li and Wu [44] & 604 & -566 & 80 & 99 & 58 \\
Zhang and Webb [45] & 781 & -768 & 73 & 99 & 42 \\
Li and Wu [46] & 694 & 633 & 59 & 66 & 51 \\
Kim and Mudawar [47] & 567 & -552 & 83 & 100 & 63 \\
\hline & & & & & 76 \\
\hline Beggs and Brill [26] & 213 & -141 & 89 & 100 & \\
\hline
\end{tabular}

In the case of the homogeneous flow models, it is supposed that the two phases are flowing at the same velocity. Consequently, a two-phase flow Reynolds number is considered to calculate the fanning friction factor $f_{t p}$ :

$\frac{d P_{\text {frict }}}{d z}=\frac{2 f_{t p} G^{2}}{\rho_{t p} d}$

where $\rho_{t p}=\left[\frac{x}{\rho_{v a p}}+\frac{1-x}{\rho_{\text {liq }}}\right]^{-1}$ is the two-phase density.

The expression of the Reynolds number is the following one:

$R e_{t p}=\frac{G d}{\mu_{t p}}$

where $\mu_{t p}$ is the two-phase flow dynamic viscosity.

Each homogeneous flow model is defined by the chosen expression of this viscosity. This expression depends on the phase viscosities, on the vapour quality and eventually on the phase densities ([29,30,32,34]). Consequently, all these models, developed with horizontal and vertical data, do not take into account the effect of inclination. The total pressure drop is then calculated by summing the calculated frictional term with the gravitational one considering the homogeneous void fraction $\left(\varepsilon_{h}\right)$ expression:

$\left(\frac{d P_{\text {tot }}}{d z}\right)_{h}=\left(\frac{d P_{\text {frict }}}{d z}\right)_{h}+\left[\varepsilon_{h} \rho_{\text {vap }}+\left(1-\varepsilon_{h}\right) \rho_{\text {liq }}\right] g \sin \beta$

with $\varepsilon_{h}=\left[1+\left(\frac{1-x}{x}\right) \frac{\rho_{\text {vap }}}{\rho_{\text {liq }}}\right]^{-1}$

In the case of a separated flow model, the liquid and vapour phases are considered to separately flow in two different channels. Except in the case of Müller-Steinhagen and Heck model [38] where the twophase pressure drop is calculated from the limit cases of liquid only and vapour only flows, a two-phase multiplier is used to calculate the two-phase pressure drop from the one-phase case (liquid or vapour): 
$\left(\frac{d P_{\text {frict }}}{d z}\right)_{t p}=\left(\frac{d P_{\text {frict }}}{d z}\right)_{l i q} \Phi_{\text {liq }}^{2}=\left(\frac{d P_{\text {frict }}}{d z}\right)_{\text {vap }} \Phi_{v a p}^{2}$

or

$\left(\frac{d P_{\text {frict }}}{d z}\right)_{t p}=\left(\frac{d P_{\text {frict }}}{d z}\right)_{l i q, o} \Phi_{\text {liq }, o}^{2}=\left(\frac{d P_{\text {frict }}}{d z}\right)_{\text {vap }, o} \Phi_{\text {vap }, o}^{2}$

where $\Phi_{l i q}$ and $\Phi_{v a p}$ are respectively the liquid and vapour two-phase multipliers. $\Phi_{l i q, o}$ and $\Phi_{v a p, o}$ are the liquid only and vapour only two-phase multipliers.

The total pressure gradient is then calculated by summing the frictional contribution coming from the model and the gravitational pressure gradient. In the present study, this last term is calculated considering the void fraction correlation of Bhagwat and Ghajar [19].

Among the homogeneous flow models tested, the model of Dukler et al. [29] presents the best agreement with the experimental data in terms of percentage of experimental data captured. The models of Friedel [37] and Kim and Mudawar [47] are the best separated flow models tested. Whatever the tested model, the predictions are always better for upward flows than for downward flows since PEDC50+ is constantly higher than PEDC50-. It is consistent with the behaviour of the frictional pressure drop. Inclination slightly affects frictional pressure drops for the horizontal and upward flows while in the case of a downward flow, it strongly depends on the inclination. Consequently, these models being mainly developed from horizontal datasets, they predict well the effect of inclination on the total pressure drops only for the upward flows.

The separated flow and homogeneous flow models do not take into account the effect of inclination on the frictional pressure gradient. Among the few models taking into consideration the effect of inclination for the prediction of the pressure drop [3,26,48], the model of Beggs and Brill [26], developed with airwater flows in macro-channels of 25.4 and $38,1 \mathrm{~mm}$ inner diameter, is tested in the present study. Inclination is taken into account for the calculation of the total pressure gradient through the expression of the gravitational pressure gradient and the liquid holdup. The liquid holdup is first calculated for the horizontal case, depending on the flow pattern prediction. Then, it is adjusted from the horizontal case by considering the deviation induced by the inclination.

The model showed a better agreement with the experimental dataset since all the statistical indicators are better for the Beggs and Brill model [26] than for the homogeneous and separated flow models. However, the intensity of the variations of the predicted frictional pressure gradient is lower than the experimental ones as shown in Figure 14. 
$\Delta$ Intermittent $\mathbf{a}$ Stratified Annular

- Beggs and Brill [11] predictions

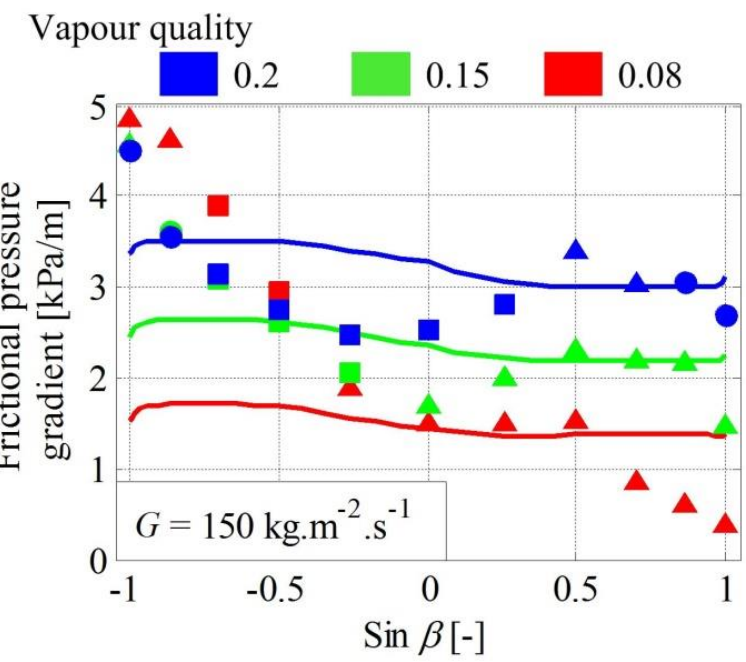

Figure 14: Comparison of Beggs and Brill [26] model predictions of the frictional pressure gradient with the experimental dataset for a mass velocity of $150 \mathrm{~kg} \cdot \mathrm{m}^{-2} \cdot \mathrm{s}^{-1}$

As a conclusion, the analysis of the homogeneous and separated flow model predictions showed these models can be appropriate for the prediction of the pressure gradient for upward flows but are unable to predict the pressure gradient for downward flows. The empirical model of Beggs and Brill [26], developed for inclined flows, shows better agreements than the other models but under predicts the intensity of the variations of the pressure gradient with inclination.

It can be explained by the fact that the pressure drop models developed in the literature for horizontal or vertical flows, as those proposed in Table 3, are generally independent of the flow patterns for the pre dryout region. As a result, the change of behaviour observed in our data with respect to the tilt angle cannot be correctly predicted. Furthermore, the maximum of the pressure drop observed at high vapour quality is almost never predicted correctly in any model available, which increases the disagreement between our data and the models.

From a phenomenological point of view, for annular flow, which is one of the main flow regime encountered, the pressure drop is mainly related to the interfacial shear stress that can be linked to the liquid film inertia. If the Reynolds number of the liquid film increases, some waves may develop up to reach a maximum amplitude (critical Reynolds number). As a result, the interfacial friction factor will increase and the pressure drop will be affected. During partial dryout, the passage from annular to stratified flow regime for instance, the shear stress at the wall will be significantly different from that at the interface. Sine gravity force may affect the flow patterns and the instabilities of the liquid film, it is logical to see an influence on pressure drop. Further studies are needed to be able to quantitatively predict the effect of inclination on the pressure gradient. 


\subsection{Effect of heat flux on the pressure drops}

It was observed that heating two-phase flow affects the flow pattern transitions. The nucleation bubbles perturb the liquid-vapour interface, which causes the disappearance of the stratified flow. Pressure drops are strongly conditioned by the dynamic of the liquid-vapour interface since they result in part from friction between the two phases. Consequently, the fact of heating the flow increases the pressure drop as it is shown in Figure 15, which presents some results of both campaigns under adiabatic and diabatic conditions. Note that in this figure, the momentum pressure drop, which is affected when a heat flux is applied, has been removed from the total pressure drop. This observation was previously made by Quibén and Thome [49] in $8 \mathrm{~mm}$ and $13.8 \mathrm{~mm}$ inner diameter horizontal channels. However, the intensity of the offset is higher in the present case ( $2 \mathrm{kPa} \cdot \mathrm{m}^{-1}$ compared to $0.1 \mathrm{kPa} \cdot \mathrm{m}^{-1}$ [49]). This is possibly due to the higher confinement and the higher flux of the present study. In these conditions, the flux disturbs more the flow, which results in a higher difference between the adiabatic and diabatic cases.

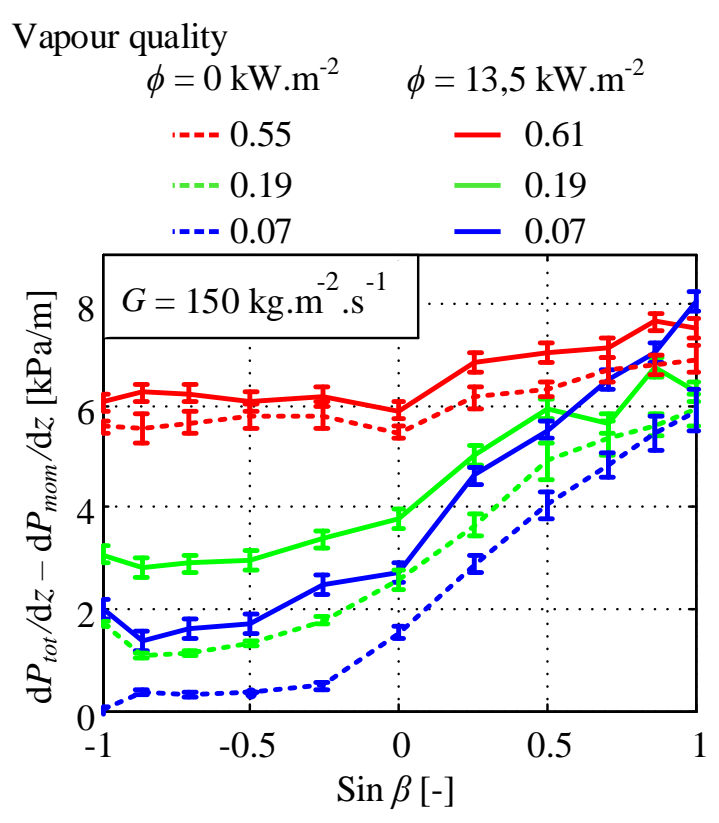

Figure 15: Comparison of the pressure gradient variations with the inclination angle with an imposed heat flux of $13.5 \mathrm{~kW} \cdot \mathrm{m}^{-2}$ (filled lines) and without heat flux (dot lines)

The observed offset is slightly affected by the inclination. However, it is noticeable that the difference of the pressure gradients decreases with the vapour quality. This observation is consistent with the idea that when the vapour quality increases, the intensity of the nucleation decreases and the flow is less disturbed. Consequently, the effect of the heat flux vanishes.

As a conclusion, the heat flux appears to increase the total pressure drops (corrected from the momentum pressure drop) and this increase mainly depends on the vapour quality while very slightly on the inclination. To better understand the role of the nucleation in the increase of the pressure drops, it would be appropriate to perform studies with several heat fluxes and to diversify the test configurations, especially in terms of confinement. 


\section{Conclusions}

Flow boiling experiments were carried out in a smooth inclined mini-channel with R245fa for the whole range of inclination. The transparency of the evaporator enabled the visualisation of the effect of the heat flux on the flow patterns. All the tests were conducted with a saturation temperature of $81^{\circ} \mathrm{C}$, vapour quality ranging from 0.03 to 0.85 , mass velocity from 100 to $300 \mathrm{~kg} \cdot \mathrm{m}^{-2} \cdot \mathrm{s}^{-1}$. The imposed heat flux density was $13.5 \mathrm{~kW} \cdot \mathrm{m}^{-2}$ in the case of the diabatic experiments.

The effect of inclination on the flow patterns and the pressure drops was studied in both adiabatic and diabatic conditions. The study of the flow pattern transitions showed a clear effect of the gravity forces orientation on the flow patterns for low inertia two-phase flows. This observation was compared with the predictions of the models of Barnea [4] and Crawford et al. [5,6]. The model of Barnea [4] showed a particularly good agreement with the observed flow pattern transitions. When a heat flux was imposed, the stratified flow disappeared for the low inertia flows. The nucleation bubbles seem to perturb the liquid-vapour interface, keeping intermittent flow for the downward inclinations.

The measurement of the pressure drops showed a clear effect of inclination for the low inertia two-phase flows in both adiabatic and diabatic conditions. The variations of the pressure drops with inclination were similar to those which were observed in previous macro-channel experiments. A transition was observed between the downward and upward flows, corresponding to the transition between stratified and intermittent flows in the case of adiabatic conditions. The pressure drop measurements were compared with usual homogeneous and separated flow models and showed that the best models were able to well anticipate the evolution of the total pressure drops for the upward flows. However, since the frictional pressure drop roughly increases for the downward flows, these models are not adapted to predict the pressure drops in this configuration. The predictions of the empirical model of Beggs and Brill [26] were tested and showed the best agreement with the present dataset. However, this model remains unable to predict the evolution of the pressure drops for the downward flows. The heat flux appeared to increase the pressure drops and this increase does not depend on the inclination. This effect vanishes when the vapour quality increases.

As a conclusion, flow patterns and pressure drops appeared to be affected by the inclination for low inertia flows even in the high confinement conditions of the present study. Both flow patterns and pressure drops were impacted by the heat flux in the present study. This suggests multiplying studies with transparent evaporators in inclined configurations.

\section{Appendix A. Supplementary data}

Supplementary data associated with this article can be found in the online version DOI

\section{References}

[1] Charnay R. Experimental study of flow boiling in horizontal minichannels at high saturation temperature. Lyon, INSA, 2014. 
[2] Lips S, Meyer JP. Two-phase flow in inclined tubes with specific reference to condensation: A review. Int J Multiphase Flow 2011;37:845-59. doi:10.1016/j.ijmultiphaseflow.2011.04.005.

[3] Taitel Y, Dukler AE. A model for predicting flow regime transitions in horizontal and near horizontal gas-liquid flow. AIChE J 1976;22:47-55. doi:10.1002/aic.690220105.

[4] Barnea D. A unified model for predicting flow-pattern transitions for the whole range of pipe inclinations. Int J Multiphase Flow 1987;13:1-12. doi:10.1016/0301-9322(87)90002-4.

[5] Weisman J, Kang SY. Flow pattern transitions in vertical and upwardly inclined lines. Int J Multiphase Flow 1981;7:271-91. doi:10.1016/0301-9322(81)90022-7.

[6] Crawford TJ, Weinberger CB, Weisman J. Two-phase flow patterns and void fractions in downward flow. Part I: steady-state flow patterns. Int J Multiphase Flow 1985;11:761-82. doi:10.1016/0301-9322(85)90023-0.

[7] Bhagwat SM, Ghajar AJ. Experimental investigation of non-boiling gas-liquid two phase flow in downward inclined pipes. Experimental Thermal and Fluid Science 2017;89:219-37. doi:10.1016/j.expthermflusci.2017.08.020.

[8] Bhagwat SM, Ghajar AJ. Experimental investigation of non-boiling gas-liquid two phase flow in upward inclined pipes. Experimental Thermal and Fluid Science 2016;79:301-18. doi:10.1016/j.expthermflusci.2016.08.004.

[9] Mohseni SG, Akhavan-Behabadi MA. Flow pattern visualization and heat transfer characteristics of R-134a during evaporation inside a smooth tube with different tube inclinations. International Communications in Heat and Mass Transfer 2014;59:39-45. doi:10.1016/j.icheatmasstransfer.2014.10.018.

[10] Ozer AB, Oncel AF, Hollingsworth DK, Witte LC. A method of concurrent thermographicphotographic visualization of flow boiling in a minichannel. Experimental Thermal and Fluid Science 2011;35:1522-9. doi:10.1016/j.expthermflusci.2011.07.002.

[11] Narcy M, de Malmazet E, Colin C. Flow boiling in tube under normal gravity and microgravity conditions. International Journal of Multiphase Flow 2014;60:50-63. doi:10.1016/j.ijmultiphaseflow.2013.11.011.

[12] Lips S, Meyer JP. Effect of gravity forces on heat transfer and pressure drops during condensation of R134a. Microgravity Sci Technol 2012;24:157-64. doi:10.1007/s12217-011-9292-3.

[13] Adelaja AO, Dirker J, Meyer JP. Experimental study of the pressure drop during condensation in an inclined smooth tube at different saturation temperatures. International Journal of Heat and Mass Transfer 2017;105:237-51. doi:10.1016/j.ijheatmasstransfer.2016.09.098.

[14] Charnay R, Revellin R, Bonjour J. Flow boiling characteristics of R-245fa in a minichannel at medium saturation temperatures. Experimental Thermal and Fluid Science 2014;59:184-94. doi:10.1016/j.expthermflusci.2014.01.011.

[15] Layssac T. Contribution à l'étude phénoménologique de l'ébullition convective en mini-canal. Thèse de doctorat. INSA de Lyon, Université de Lyon, 2018.

[16] Karayiannis TG, Mahmoud MM. Flow boiling in microchannels: Fundamentals and applications. Applied Thermal Engineering 2017;115:1372-97. doi:10.1016/j.applthermaleng.2016.08.063.

[17] Donniacuo A, Charnay R, Mastrullo R, Mauro AW, Revellin R. Film thickness measurements for annular flow in minichannels: Description of the optical technique and experimental results. Experimental Thermal and Fluid Science 2015;69:73-85. doi:10.1016/j.expthermflusci.2015.07.005.

[18] Layssac T, Capo C, Lips S, Mauro AW, Revellin R. Prediction of symmetry during intermittent and annular horizontal two-phase flows. International Journal of Multiphase Flow 2017;95:91100.

[19] Bhagwat SM, Ghajar AJ. A flow pattern independent drift flux model based void fraction correlation for a wide range of gas-liquid two phase flow. International Journal of Multiphase Flow 2014;59:186-205. doi:10.1016/j.ijmultiphaseflow.2013.11.001.

[20] Lips S, Meyer JP. Experimental study of convective condensation in an inclined smooth tube. Part II: Inclination effect on pressure drop and void fraction. Int J Heat Mass Transfer 2012;55:40512. doi:10.1016/j.ijheatmasstransfer.2011.09.034.

[21] Nicholson MK, Aziz K, Gregory GA. Intermittent two phase flow in horizontal pipes: predictive models. The Canadian Journal of Chemical Engineering 1978;56:653-663. 
[22] Barnea D, Shoham O, Taitel Y, Dukler AE. Flow pattern transition for gas-liquid flow in horizontal and inclined pipes. Comparison of experimental data with theory. Int J Multiphase Flow 1980;6:217-226. doi:https://doi.org/10.1016/0301-9322(80)90012-9.

[23] Rouhani S., Axelsson E. Calculation of void volume fraction in the subcooled and quality boiling regions. Int J Heat Mass Transfer 1970;13:383-93. doi:10.1016/0017-9310(70)90114-6.

[24] Steiner D. Heat transfer to boiling saturated liquids. VDI-Wārmeatlas (VDI Heat Atlas), Verein Deutscher Ingenieure, VDI-Gesellschaft Verfahrenstechnik Und Chemieingenieurwesen (GCV), Düsseldorf, Chapter Hbb 1993.

[25] Spedding PL, Chen JJJ, Nguyen VT. Pressure drop in two phase gas-liquid flow in inclined pipes. Int J Multiphase Flow 1982;8:407-31. doi:10.1016/0301-9322(82)90050-7.

[26] Beggs DH, Brill JP. A study of two-phase flow in inclined pipes. J Pet Technol 1973;25:607-17. doi:10.2118/4007-PA.

[27] McAdams WH, Woods WK, Bryan RL. Vaporization inside horizontal tubes-II-Benzene-oil mixtures. Trans ASME 1942;64:193.

[28] Cicchiti A, Lombardi C, Silvestri M, Soldaini G, Zavattarelli R. Two-phase cooling experiments: pressure drop, heat transfer and burnout measurements 1959.

[29] Dukler AE, Wicks M, Cleveland RG. Pressure drop and hold-up in two-phase flow Part largelsc A-A comparison of existing correlations and Part largelsc B-An approach through similarity analysis. AIChE J 1964;10:38-51.

[30] Beattie DRH, Whalley PB. A simple two-phase frictional pressure drop calculation method. International Journal of Multiphase Flow 1982;8:83-87.

[31] Lin S, Kwok CCK, Li RY, Chen ZH, Chen ZY. Local frictional pressure drop during vaporization of R-12 through capillary tubes. Int J Multiphase Flow 1991;17:95-102.

[32] Fourar M, Bories S. Experimental study of air-water two-phase flow through a fracture (narrow channel). International Journal of Multiphase Flow 1995;21:621-637.

[33] Davidson WF, Hardie PH, Humphreys CGR, Markson AA, Mumford AR, Ravese T. Studies of heat transmission through boiler tubing at pressures from 500 to 3300 pounds. Trans ASME 1943;65:553-591.

[34] García F, García R, Padrino J., Mata C, Trallero J., Joseph D. Power law and composite power law friction factor correlations for laminar and turbulent gas-liquid flow in horizontal pipelines. International Journal of Multiphase Flow 2003;29:1605-24. doi:10.1016/S0301-9322(03)001393.

[35] Awad MM, Muzychka YS. Effective property models for homogeneous two-phase flows. Experimental Thermal and Fluid Science 2008;33:106-13. doi:10.1016/j.expthermflusci.2008.07.006.

[36] Lockhart RW, Martinelli RC. Proposed correlation of data for isothermal two-phase, twocomponent flow in pipes. Chem Eng Prog 1949;45:39-48.

[37] Friedel L. Improved friction pressure drop correlations for horizontal and vertical two phase pipe flow. 3R International, Heft 7 1979;18:485-491.

[38] Müller-Steinhagen H, Heck K. A simple friction pressure drop correlation for two-phase flow in pipes. Chem Eng Process 1986;20:297-308.

[39] Mishima K, Hibiki T, Nishihara H. Some characteristics of gas-liquid flow in narrow rectangular ducts. Int J Multiphase Flow 1993;19:115-124.

[40] Tran TN, Chyu M-C, Wambsganss MW, France DM. Two-phase pressure drop of refrigerants during flow boiling in small channels: an experimental investigation and correlation development. Int J Multiphase Flow 2000;26:1739-54. doi:https://doi.org/10.1016/S0301-9322(99)00119-6.

[41] Chen IY, Yang KS, Chang YJ, Wang CC. Two-phase pressure drop of air-water and R-410A in small horizontal tubes. Int J Multiphase Flow 2001;27:1293-9.

[42] Yu W, France DM, Wambsganss MW, Hull JR. Two-phase pressure drop, boiling heat transfer, and critical heat flux to water in a small-diameter horizontal tube. Int $\mathbf{J}$ Multiphase Flow 2002;28:927-41.

[43] Hwang YW, Kim MS. The pressure drop in microtubes and the correlation development. Int $\mathbf{J}$ Heat Mass Transfer 2006;49:1804-12.

[44] Li W, Wu Z. A general correlation for adiabatic two-phase pressure drop in micro/mini-channels. International Journal of Heat and Mass Transfer 2010;53:2732-2739. 
[45] Zhang M, Webb RL. Correlation of two-phase friction for refrigerants in small-diameter tubes. Exp Therm Fluid Sci 2001;25:131-9.

[46] Li W, Wu Z. Generalized adiabatic pressure drop correlations in evaporative micro/mini-channels. Experimental Thermal and Fluid Science 2011;35:866-72. doi:10.1016/j.expthermflusci.2010.07.005.

[47] Kim S-M, Mudawar I. Review of databases and predictive methods for pressure drop in adiabatic, condensing and boiling mini/micro-channel flows. International Journal of Heat and Mass Transfer 2014;77:74-97. doi:10.1016/j.ijheatmasstransfer.2014.04.035.

[48] Mukherjee H, Brill JP. Pressure drop correlations for inclined two-phase flow. J Energy Resour Technol 1985;107:549-54. doi:10.1115/1.3231233.

[49] Quibén JM, Thome JR. Flow pattern based two-phase frictional pressure drop model for horizontal tubes, Part ItextnormalII: New phenomenological model. Int J Heat Fluid Flow 2007;28:1060-72. 